\author{
SANDIA REPORT \\ SAND2012-3006 \\ Unlimited Release \\ April 2012
}

\title{
Localized Temperature Stability in Low Temperature Cofired Ceramics (LTCC)
}

Steve X. Dai and Lung-Hwa Hsieh

Prepared by

Sandia National Laboratories

Albuquerque, New Mexico 87185 and Livermore, California 94550

Sandia National Laboratories is a multi-program laboratory managed and operated by Sandia Corporation, a wholly owned subsidiary of Lockheed Martin Corporation, for the U.S. Department of Energy's

National Nuclear Security Administration under contract DE-AC04-94AL85000.

Approved for public release; further dissemination unlimited. 
Issued by Sandia National Laboratories, operated for the United States Department of Energ y by Sandia Corporation.

NOTICE: This report was pr epared as an account of work sponsored b y an agency of the United States Government. Neither the United States Government, nor any agency thereof, nor any of their employees, nor any of their co ntractors, subcontractors, or their emplo yees, make any warranty, express or implied, or assume an y legal liability or responsibility for the accuracy, completeness, or usefulness of an y information, apparatus, product, or process disclosed, or represent that its use would not infringe privately owned rights. Reference herein to any specific commercial $\mathrm{p}$ roduct, process, or service $\mathrm{b}$ y trade name, trademark, manufacturer, or otherwise, do es not necessari ly constitute or imply its endorsement, recommendation, or favoring by the United States Government, any agency thereof, or any of their contractors or subcontractors. The view $\mathrm{s}$ and opinions expressed h erein do not necessarily state or reflect those of the United States Government, any agency thereof, or any of their contractors.

Printed in the United States of America. This report has been reproduced directly from the best available copy.

Available to DOE and DOE contractors from

U.S. Department of Energy

Office of Scientific and Technical Information

P.O. Box 62

Oak Ridge, TN 37831

Telephone: $\quad$ (865) 576-8401

Facsimile: $\quad$ (865) 576-5728

E-Mail: $\quad$ reports@adonis.osti.gov

Online ordering: http://www.osti.gov/bridge

Available to the public from

U.S. Department of Commerce

National Technical Information Service

5285 Port Royal Rd.

Springfield, VA 22161

Telephone: $\quad$ (800) 553-6847

Facsimile: $\quad$ (703) 605-6900

E-Mail: $\quad$ orders@ntis.fedworld.gov

Online order: $\quad$ http://www.ntis.gov/help/ordermethods.asp?loc=7-4-0\#online

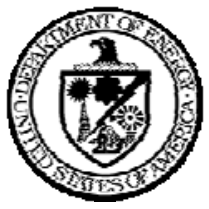


SAND2012-3006

Unlimited Release

April 2012

\title{
Localized Temperature Stability in Low Temperature Cofired Ceramics (LTCC)
}

\author{
Steve X. Dai* and Lung-Hwa Hsieh ${ }^{\#}$ \\ *01832, Advanced Prototyping S\&T \\ \#5353, Radar Fuzing Department \\ Sandia National Laboratories \\ P.O. Box 5800 \\ Albuquerque, New Mexico 87185-MS0959
}

\begin{abstract}
The base d ielectrics of commercial low tem perature cofired ceram ics (LTCC) systems have a temperature coefficient of resonant frequency $\left(\tau_{\mathrm{f}}\right)$ in the range $-50 \sim$ $80 \mathrm{ppm} /{ }^{\circ} \mathrm{C}$. In this research we explored a method to realize zero or near zero $\tau_{\mathrm{f}}$ resonators by incorporating $\tau_{\mathrm{f}}$ compensating materials locally into a multilayer LTCC structure. To select composition for $\tau_{\mathrm{f}}$ adjustment, $\tau_{\mathrm{f}}$ compensating $\mathrm{m}$ aterials with different amount of $t$ itanates were form ulated, synthesized, and characterized. Chemical interactions and physic al compatibility between the $\tau_{\mathrm{f}}$ modifiers and the host LTCC diele ctrics were investigated. Studies on stripline (SL) resonator panels with multiple compensating dielectrics revealed that: 1) co mpositions using $\mathrm{SrTiO}_{3}$ provide the largest $\tau_{f}$ adjustment among titanates, 2 ) the $\tau_{f}$ compensation is proportional to the amount of $\mathrm{SrT} \mathrm{iO}_{3}$ in compensating mater ials, as well a s the thickness of the com pensating layer, and 3 ) th e most effective $\tau_{\mathrm{f}}$ compensation is achieved when the compensating dielectric is integrated next to the SL. Using the effective dielectric con stant of a heterog eneous layered dielectric structure, results from Method of Mom entum (MoM) electromagnetic simulations are consistent with the experimental observations.
\end{abstract}




\section{ACKNOWLEDGMENTS}

The authors thank Tom Chavez, Adrian Cas ias, Shelley Williams, Adrian Wagner and Dennis De Smet for help in sample fabrication and m easurement, and Dr Robe rt Grubbs and Dr Kevin Ewsuk for their critical review of the m anuscript. This work was supported by the Laboratory Directed Research and Developm ent program at Sandia National Laboratories, a m ulti-program laboratory managed and operated by Sandia Corporation, a wholly owned subsidiary of Lockheed Martin Corporation, for the U.S. De partment of Energy's National Nuclear Security Administration under contract DE-AC04-94AL85000. 


\section{CONTENTS}

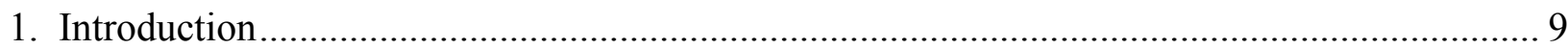

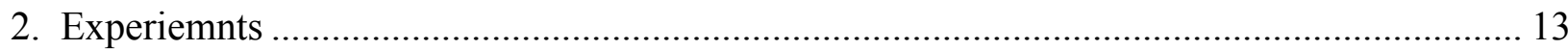

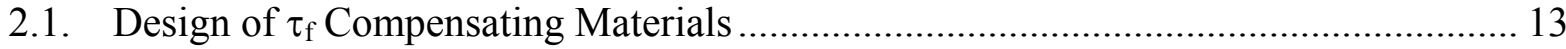

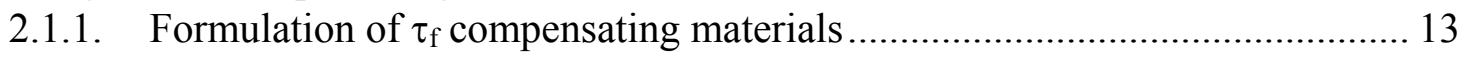

2.1.2. Synthesis of $\tau_{\mathrm{f}}$ compensating materials ........................................................ 14

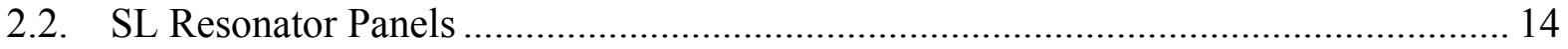

2.2.1. Construction of panels ................................................................................ 14

2.2.2. Incorporation of $\tau_{\mathrm{f}}$ adjusters in resonator panels ......................................... 15

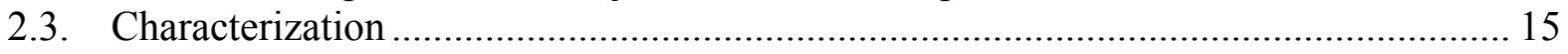

2.3.1. $\tau_{\mathrm{f}}$ compensating materials ......................................................................... 15

2.3.2. SL resonator panels ................................................................................. 16

3. Calculation of Effective Dielectric Constant and Simulation of Resonant Frequency............. 17

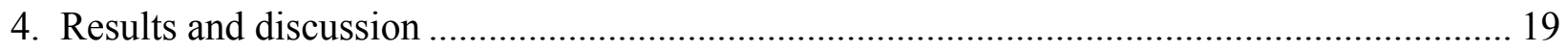

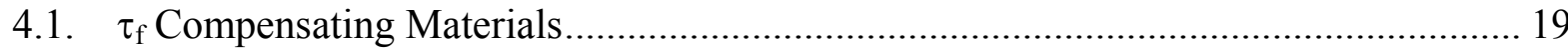

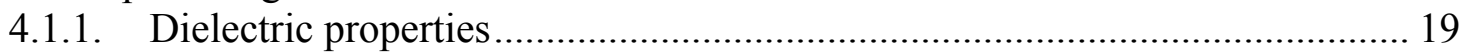

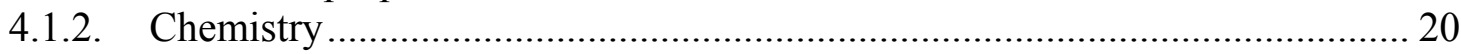

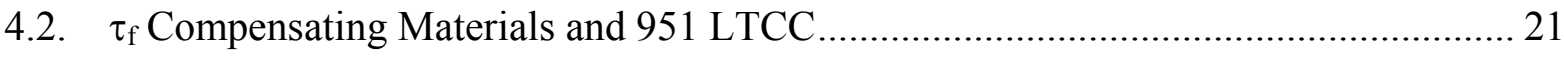

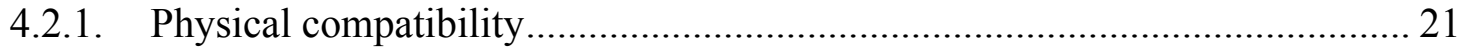

4.2.2. Chemical compatibility ............................................................................ 22

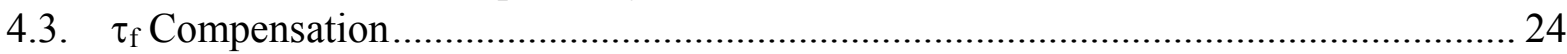

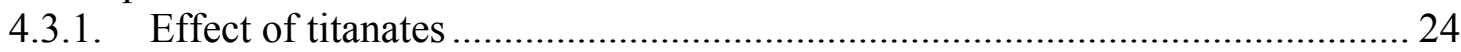

4.3.2. Effect of glass and STO content ……………………………………… 25

4.3.3. Effect of STO layer thickness ………………….................................... 26

4.3.4. Effect of STO configuration ………………….......................................... 26

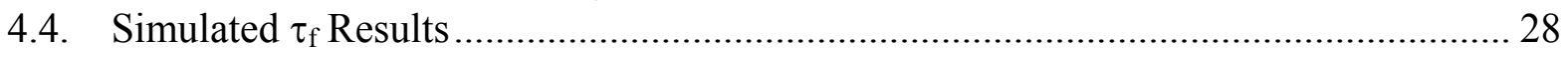

4.4.1. Effect of STO composition and thickness ………..................................... 28

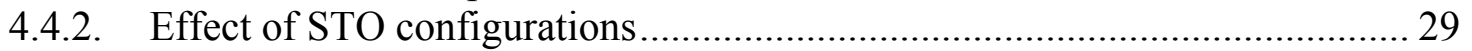

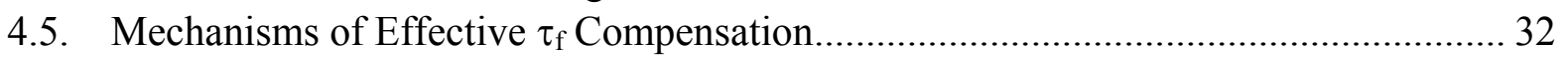

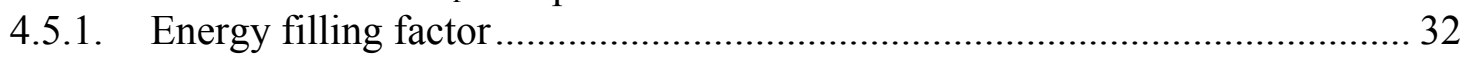

4.5.2. Energy concentration in STO dielectrics in case 1 ...................................... 32

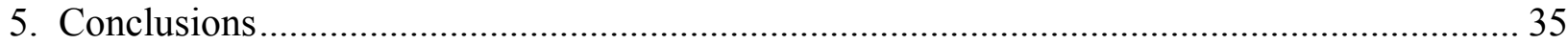

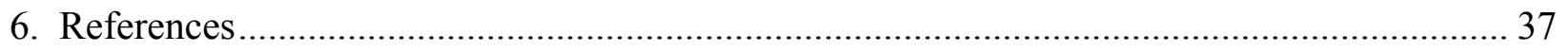

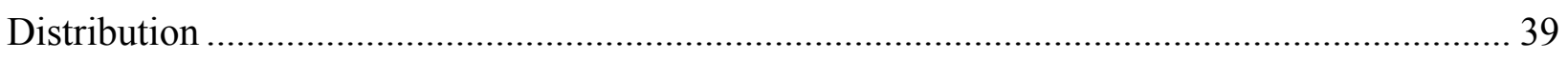




\section{FIGURES}

Figure 1. $\tau_{\mathrm{f}}$ of several commercial LTCC base dielectrics from DuPont, Ferro and Hereaus. The resonant frequencies $\mathrm{f}_{\mathrm{r}}$ (all $\left.\sim 1.5 \mathrm{GHz}\right)$ were collected from SL ring resonators from -50 to $80{ }^{\circ} \mathrm{C}$, and normalized to $\mathrm{f}_{\mathrm{r}}$ at $20^{\circ} \mathrm{C}$.

Figure 2. Au ring resonator and feed lines on $75 \times 75 \mathrm{~mm}$ green (left) and sintered (right) 951 tape with a printed STO layer in between............................................................. 14

Figure 3. Green, sintered, and finished SL resonator panels. ............................................. 15

Figure 4. $f_{\mathrm{r}}$ test setup, and the mounting of a SL resonator panel.............................................. 16

Figure 5. Admittance from dielectric interfaces. ............................................................... 17

Figure 6. XRD of sintered compensating materials, STO10 and STO20, compared to the

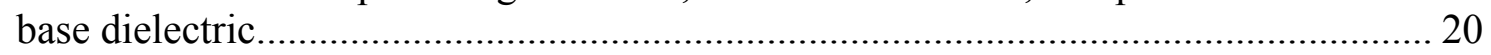

Figure 7. SEM image and element mapping of STO20 ........................................................ 21

Figure 8. Shrinkage curves and onset temperatures of CMB STO20 and 951 LTCC.................. 22

Figure 9. a) Optical cross section of sintered CMB STO20 on 951, and b) a SEM cross section of the interface between the CMB STO20 and the 951 LTCC. ....................... 22

Figure 10. Embedded CMB STO20 in a 4 layer 951 LTCC, a) one side, and b) both sides of

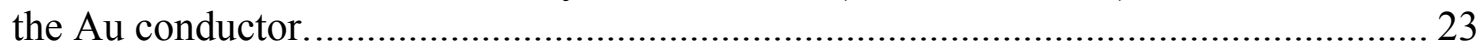

Figure 11. a) SEM cross-section image of cofired STO20 dielectric and Au resonator line; b) mapping of Si element in a); c) SEM image of embedded STO20 in 951 LTCC. The correspondent element maps for Al, Sr and Ti are shown in d), e) and f)............. 23

Figure 12. Tempeature dependence of normalized $\varepsilon$ of compensating materials......................... 24

Figure 13. Three configurations of printed STO layers examined. ........................................ 27

Figure 14. $\varepsilon_{\text {eff }}$ of SL as a function of temperature and STO layer thicknesses from 5 to $50 \mu$ m.... 28

Figure 15. Simulated $\mathrm{f}_{\mathrm{r}}$ of SL resonators as a function of temperature at STO layer

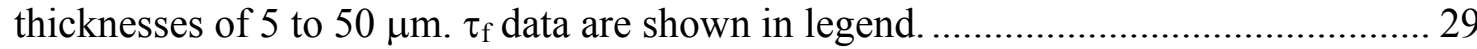

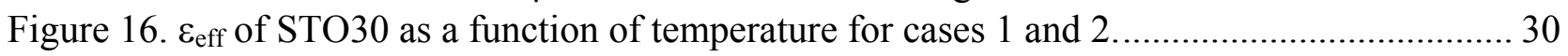

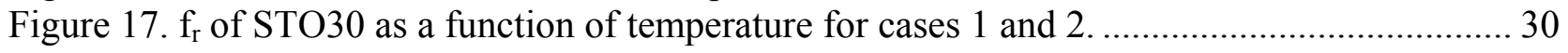

Figure 18. $\tau_{\mathrm{f}}$ of SL resonators from simulation (solid lines) and experiment (discrete points)...... 31

\section{TABLES}

Table 1. Potential compensating materials.

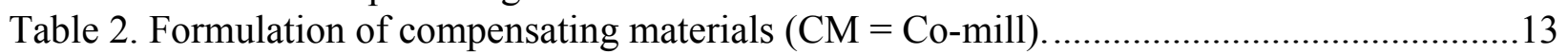

Table 3. Dielectric constant of $\tau_{\mathrm{f}}$ compensating materials from $-50{ }^{\circ} \mathrm{C}$ to $80{ }^{\circ} \mathrm{C}$......................19

Table 4. Density, room temperature dielectric constant $\varepsilon, \tau_{\varepsilon}$, and estimated $\tau_{\mathrm{f}}$ of compensating materials.

Table 5. $\tau_{\mathrm{f}}$ data for SL resonators using different STO compositions and a layer thickness of approximately $20 \mu \mathrm{m}$. .25

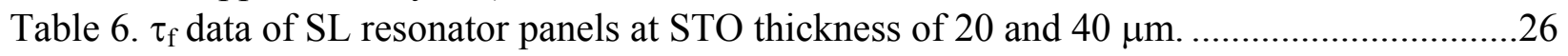

Table 7. Dielectric layer in the three configurations used in this study.....................................27

Table 8. $\tau_{\mathrm{f}}$ of SL resonators with different STO layer thicknesses and configurations................27 


\section{NOMENCLATURE}

$\alpha$

CTE

CTO

CM

CMA

$\mathrm{CMB}$

$\mathrm{CM}$

$\varepsilon$

$\mathrm{f}_{\mathrm{r}}$

LTCC

MW

RF

SL

STO

TO

$\tau_{\mathrm{c}}$

$\tau_{\varepsilon}$

$\tau_{\mathrm{f}}$
Temperature coefficient of expansion

Temperature coefficient of expansion

$\mathrm{CaTiO}_{3}$

Co-Mill

Co-Mill powders with $\mathrm{V}$-glass at $60 \mathrm{wt} \%$

Co-Mill powders with $\mathrm{V}$-glass at $55 \mathrm{wt} \%$

Co-Mill powders with $\mathrm{V}$-glass at $49.5 \mathrm{wt} \%$

Dielectric constant

Resonant frequency

Low temperature co-fired ceramics

Microwave

Radio frequency

Strip-line

$\mathrm{SrTiO}_{3}$

$\mathrm{TiO}_{2}$

Temperature coefficient of capacitance

Temperature coefficient of dielectric constant

Temperature coefficient of resonant frequency 


\section{INTRODUCTION}

A low $\tau_{\mathrm{f}}$, preferably close to $0 \mathrm{ppm} /{ }^{\circ} \mathrm{C}$, is desirable to achieve resonator functions for radio and microwave frequency (RF and MW ) applications that are stable to temperature variations. By using a low $\tau_{\mathrm{f}}$ resonator the temperature compensation that requires additional mechanical [1] and electrical circuitry [2] can be eliminated. For filter applications, a low $\tau_{\mathrm{f}}$ translates into an efficient use of frequency spectrum for maximum data capacity.

There are multiple approaches to achieve temperature stable resonator functions. One common engineering method of realizing a near zero $\tau_{\mathrm{f}}$ is to form solid solutions of different dielectric ceramics that have opposite $\tau_{\mathrm{f}}$. Kell, Greenham and Ol ds [3] developed temperature-stable compositions in systems $\mathrm{Ca}(\mathrm{Zr}, \mathrm{Ti}) \mathrm{O}_{3}$ and $(\mathrm{Ba}, \mathrm{Sr})(\mathrm{Zr}, \mathrm{Ti}) \mathrm{O}_{3}$. Kucheiko et al [4] studied a $\mathrm{CaTiO}_{3^{-}}$ $\mathrm{Ca}\left(\mathrm{Al}_{1 / 2} \mathrm{Ta}_{1 / 2}\right) \mathrm{O}_{3}$ ceramic solid so lution to id entify a temperature stable composition for microwave applications. A general survey of microwave dielectrics, with an emphasis on temperature stability for resonators and filters, has been provided by Wersing [5]. In their review on microwave dielectric ceramics for mobile phone networks, Reaney and Iddles [6] summarized key factors that affect $\tau_{f}$.

Other practice to realize a low $\tau_{\mathrm{f}}$ is to form a hybrid lay ered structure incorporating alternating layers of opposite $\tau_{\mathrm{f}}$ materials. Alford et al. [7] fabricated lay ered $\mathrm{Al}_{2} \mathrm{O}_{3}-\mathrm{TiO}_{2}$ microwave dielectric resonators by sequential sintering of thick film $\mathrm{TiO}_{2}\left(\tau_{\mathrm{f}}=+450 \mathrm{ppm} /{ }^{\circ} \mathrm{C}\right)$ on $\mathrm{Al}_{2} \mathrm{O}_{3}\left(\tau_{\mathrm{f}}=\right.$ $-60 \mathrm{ppm} /{ }^{\circ} \mathrm{C}$ ) substrates. The $\tau_{\mathrm{f}}$ of the resonators could be adjusted over a wide range, including 0 $\mathrm{ppm} /{ }^{\circ} \mathrm{C}$, by varying the thickness of $\mathrm{TiO}_{2}$ layer. $\mathrm{Li}$ and $\mathrm{Che} \mathrm{n}[8]$ adopted an approach of using adhesive-bonded $\mathrm{Ca}\left(\mathrm{Mg}_{1 / 3} \mathrm{Nb}_{2 / 3}\right) \mathrm{O}_{3}$ and $\mathrm{Ba}\left(\mathrm{Zn}_{1 / 3} \mathrm{Nb}_{1 / 3}\right) \mathrm{O}_{3}$ layered composite to form dielectric resonators. The $\tau_{\mathrm{f}}$ could be tuned to $0 \mathrm{ppm} /{ }^{\circ} \mathrm{C}$ at a proper thickness ratio of the two constituents that possess opposite $\tau_{\mathrm{f}}$.

Low temperature cofired ceram ic (LTCC) is a multilayer 3D packaging, intercon nection and integration technology. An LTCC s ystem refers to a base tape dielectric, typically a glass or glass-ceramic, and conductors ( $\mathrm{Au}, \mathrm{Ag}$, Pt, etc) that are cofireable at temperatures $850 \sim 900{ }^{\circ} \mathrm{C}$. Passive integration in LTCC, lik e embedded resistors and capacitors, is realized by cofiring specially engineered dielectric and resistive materials in paste or tape forms. In the past 20 years the largest growth of LTCC technology has occu rred in wireless comm unications. The three dielectric material parameters most im portant to this applic ation space inclu de dielectric constant, $\varepsilon$, quality factor, Q (inverse of dielectric loss), and $\tau_{\text {f. }}$ For RF/MW LTCC circuits with embedded resonator functions, a near zero $\tau_{\mathrm{f}}$ is necessa ry to fully utilize the communication bandwidth.

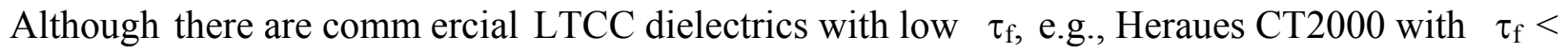
$\pm 10 \mathrm{ppm} /{ }^{\circ} \mathrm{C}$, most of existing LTCC dielectrics have a $\tau_{\mathrm{f}}$ in the range -50 to $-80 \mathrm{ppm} /{ }^{\circ} \mathrm{C}$. Figure 1 shows resonant frequency $\left(f_{r}\right)$ versus temperature curves (normalized to $f_{r}$ at $20^{\circ} \mathrm{C}$ ) f or several main stream LTCC dielectrics along with $\tau_{f}$ data from this study. It is expected that, $f$ or integrated RF circuits using these LTCCs, the impact of $\tau_{\mathrm{f}}$ will be reflected in the drift of the $\mathrm{f}_{\mathrm{r}}$ of the embedded resonator over the device's operating temperatures. Often this results in a reduced working bandwidth, and an extra design limitation and/or a performance compromise. 


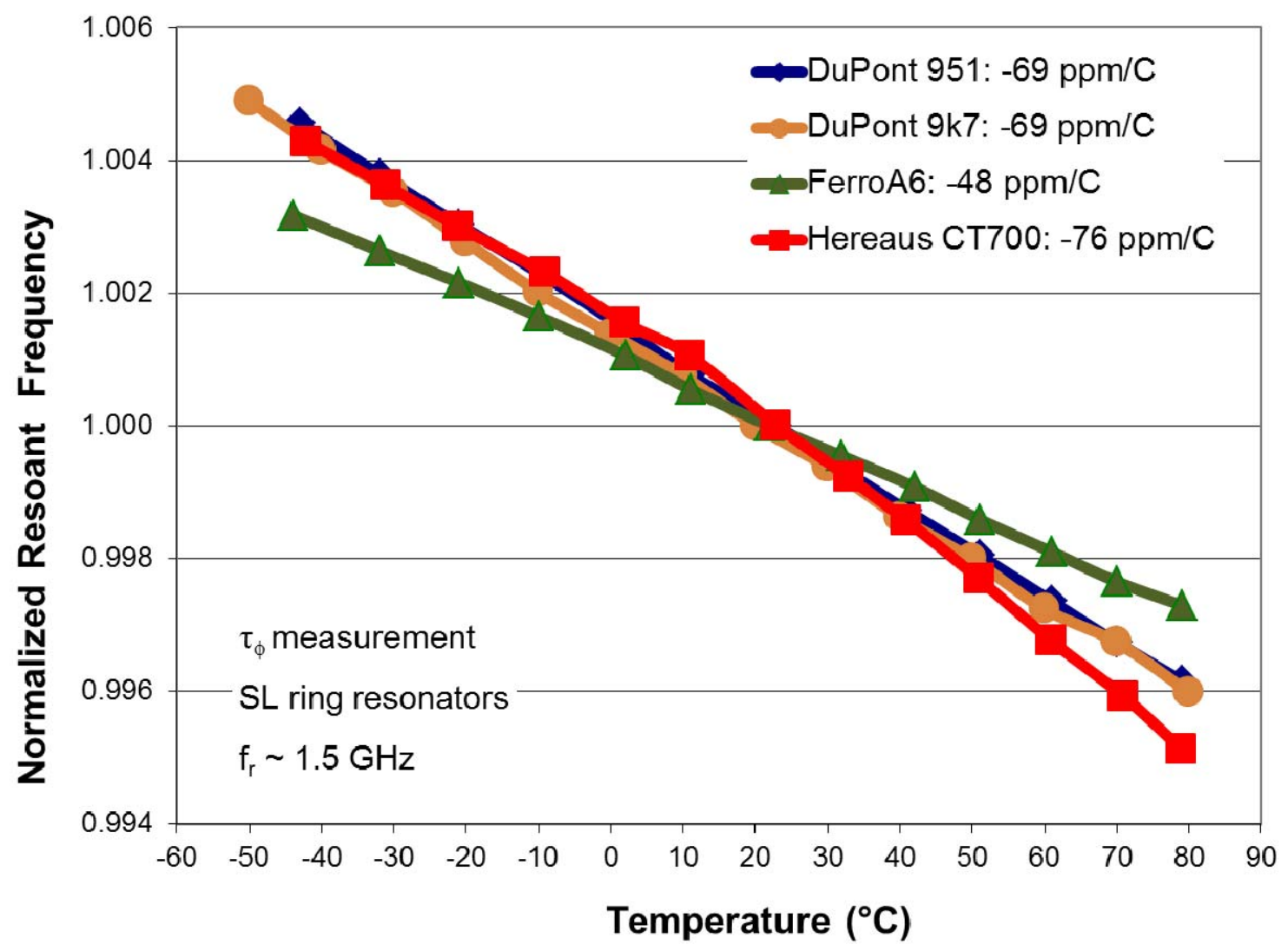

Figure 1. $\tau_{\mathrm{f}}$ of several commercial LTCC base dielectrics from DuPont, Ferro and Hereaus. The resonant frequencies $\mathrm{f}_{\mathrm{r}}($ all $\sim 1.5 \mathrm{GHz})$ were collected from SL ring resonators from -50 to $80^{\circ} \mathrm{C}$, and normalized to $f_{r}$ at $20^{\circ} \mathrm{C}$.

There have been $m$ any efforts to tune LTCC base dielectrics towards zero $\tau_{\mathrm{f}}$ for MW and RF applications. Dai, Huang, and Wilcox [9] proposed using titanates (positive $\tau_{\mathrm{f}}$ ) to compensate for the negative $\tau_{\mathrm{f}}$ of a glass-ceram ic LTCC di electric. Jantumen [10] investigated optim al compositions for $\tau_{\mathrm{f}}< \pm 10 \mathrm{pp} \mathrm{m} /{ }^{\circ} \mathrm{C}$ in a LTCC $\mathrm{c}$ onsisting of zinc borosilicate glass $\mathrm{m}$ ixed with $\mathrm{MgTiO}_{3}-\mathrm{CaTiO}_{3}$ ceramic fillers. $\mathrm{K}$ apta, Inoue and Kato [11] achieved a $\tau_{\mathrm{f}}$ of $1 \mathrm{ppm} /{ }^{\circ} \mathrm{C}$ in bismuth-based low fire dielectric ceram ics. Choi, Park, and Park [12] developed $\mathrm{m}$ iddlepermittivity LTCC dielectrics with an adjustable $\tau_{\mathrm{f}}$.

The purpose of this study is to expl ore a novel approach to adjust the $\tau_{\mathrm{f}}$ of a SL resonator in a multilayer LTCC structure by locally integrating a compensating dielectric with a $\tau_{\mathrm{f}}$ opposite to that of the host LTCC dielectric. U pon successful implementation, this method would enable temperature compensation where only the resonator circuits reside in a com pensating structure, which would avoid affecting other em bedded functions where the implemention is unnecessary or undesirable. In principle, this $\mathrm{m}$ ethod could be applied to any existing LTCC with a proper selection and development of cofireable com pensating dielectrics. A m ajor advantage of this approach is its inheren t compatibility with the existing LTCC material systems, which enables the use of existing cofireable conductors and ot her functional $\mathrm{m}$ aterials, and circumvents the need to re-develop an entirely new LTCC materials system. 
$\tau_{\mathrm{f}}$ is a device parameter that can be expressed in basic material properties:

$$
\tau_{\mathrm{f}}=-1 / 2 \tau_{\varepsilon}-\alpha
$$

where $\tau_{\varepsilon}$ is the temperature coefficient of dielectric constant, and $\alpha$ the coefficient of thermal expansion (CTE). For LTCC dielectrics, $\alpha$ is typically between $4 \sim 10 \mathrm{ppm} /{ }^{\circ} \mathrm{C}$, thus $\tau_{\varepsilon}$ dominates $\tau_{\mathrm{f} .}$

From eq. (1), it is clear that $\tau_{\mathrm{f}}$ and $\tau_{\varepsilon}$ have opposite signs. To compensate for the negative $\tau_{\mathrm{f}}$ of a LTCC, materials with a negative $\tau_{\varepsilon}$ and thus positive $\tau_{\mathrm{f}}$ are necessary. Table 1 lists dielectric constant $\varepsilon, \tau_{\varepsilon}$, and the normal sintering temperatures of candidate ceramics that could serve as compensating materials [13]. All three candidates are titanates, $\mathrm{TiO}_{2}, \mathrm{CaTiO}_{3}$ and $\mathrm{SrTiO}_{3}$.

Table 1. Potential compensating materials.

\begin{tabular}{|c|c|c|c|}
\hline Materials & Dielectric constant & $\tau_{\varepsilon}\left(\mathrm{ppm} /{ }^{\circ} \mathrm{C}\right)$ & Sintering Temp $\left({ }^{\circ} \mathrm{C}\right)$ \\
\hline \hline $\mathrm{TiO}_{2}$ & 110 & -750 & $\sim 1200$ \\
\hline $\mathrm{CaTiO}_{3}$ & 130 & -1600 & $\sim 1400$ \\
\hline $\mathrm{SrTiO}_{3}$ & 285 & -2400 & $\sim 1550$ \\
\hline
\end{tabular}

The key materials science challen ges include synthesizing the $\tau_{\mathrm{f}}$ compensating material and cofiring of the $m$ aterial with the existing LTCC system, for exa mple, DuPont 951 LTCC. Evidence of both physical com patibility, measured by $\mathrm{m}$ atched shrinkage, and chem ical compatibility, characterized by material interdiffusion, is provided in this study. Multiple factors that affect $\tau_{\mathrm{f}}$ adjustment, including the weight percenta ge of a titanate in the form ulation, the thickness of the com pensating layer, and th e placement of $\tau_{f}$ compensating materials in multilayer LTCC, are examined throughout the investigation.

Analytic equations derived from the variational $\mathrm{m}$ ethod with the transverse transm ission-line technique [14-17] are presented to calcul ate the effective dielectric constant, $\varepsilon_{\text {eff, }}$ of a SL in a symmetric multilayer LTCC structure. Th e Method of Momentum (MoM) simulated resonant frequency $\left(\mathrm{f}_{\mathrm{r}}\right)$ of the SL resonators at temperatures between $-50{ }^{\circ} \mathrm{C}$ to $80{ }^{\circ} \mathrm{C}$ is obtained based on temperature related dielectric constants of the $\tau_{\mathrm{f}}$ adjusters and LTCC. Using this $\mathrm{m}$ ethod, the thickness and configuration of STO can be optimized for the best temperature compensation. The simulated $\tau_{\mathrm{f}}$ was also compared to experimental data for model validation. 


\section{EXPERIEMNTS}

\subsection{Design of $\tau_{\mathrm{f}}$ Compensating Materials}

DuPont 951 LTCC GreenTape ${ }^{\mathrm{TM}}$, a widely used LTCC system in the industry over the last 20 years, was selected as the host dielectric system for the loca lized $\tau_{\mathrm{f}}$ compensation experiments. The 951 LTCC is a tape that is cast and dried from a slurry of a mixture of glass-ceramic (LTCC glass plus $\mathrm{Al}_{2} \mathrm{O}_{3}$ ceramic filler) dispers ed in an o rganic vehicle. To $\mathrm{m}$ atch the $951 \mathrm{LTCC}$ chemistry, an attempt was made to formulate the $\tau_{\mathrm{f}}$ compensating materials the same way, i. e., making the material a mixture of a LTCC glass and ceramic fillers. $\mathrm{Al}_{2} \mathrm{O}_{3}$ was used as the filler for the $\mathrm{b}$ ase compensating material. A series of compensating materials were formulated by replacing part of the $\mathrm{Al}_{2} \mathrm{O}_{3}$ in the composition with a titanate as the $\tau_{\mathrm{f}}$ adjuster. The main factors considered were the chemical constituents of the glass, and the gl ass softening point, $\mathrm{T}_{\mathrm{g}}$, which correlates closely to the onset temperature of shrinkage of the compensating material. Ideally, the onset temperature of shrinkage and the rate of shrinkage of the com pensating materials would match those of 951 LTCC. In addition, no or $m$ inimal interaction between the co mpensating material and the LTCC was also desirable. One specific LTCC glass, designated as V-glass, was selected for this study after an evaluation of several commercial LTCC glasses.

\subsubsection{Formulation of $\tau_{f}$ compensating materials}

Table 2 details the formulations of the compensating materials used in this study. CM stands for co-milled powders; A, B and C refer to weight percentage of V-glass at 60,55 and $49.5 \mathrm{wt} \%$; TO $=\mathrm{TiO}_{2}, \mathrm{CTO}=\mathrm{CaTiO}_{3}$ and $\mathrm{STO}=\mathrm{SrTiO}_{3}$; and the number represents weight percentage of an appropriate titanate that replaces $\mathrm{Al}_{2} \mathrm{O}_{3}$ as the filler material. Most of the compositions studies were $\mathrm{CMB}$ formulation where the base fo rmulation is $55 \mathrm{wt} \% \mathrm{~V}$-glass $+45 \mathrm{wt} \% \mathrm{Al}_{2} \mathrm{O}_{3}$ without the addition of a titanate. There we re three objectives to formulate these compositions: 1) to study the effect of the type of titanates, 2) to study the effect of the amount of a titanate, and 3) to study the effect of the LTCC glass to ceramic filler ratio on the $\tau_{\mathrm{f}}$ adjustment on a SL resonator.

Table 2. Formulation of compensating materials $(\mathrm{CM}=\mathrm{Co}-\mathrm{mill})$.

\begin{tabular}{|l|c|c|c|c|c|c|}
\hline Composition & $\begin{array}{c}\mathrm{V} \text {-glass } \\
(\mathrm{wt} \%)\end{array}$ & $\begin{array}{c}\mathrm{Al}_{2} \mathrm{O}_{3} \\
(\mathrm{wt} \%)\end{array}$ & $\begin{array}{c}\mathrm{TiO}_{2} \\
(\mathrm{wt} \%)\end{array}$ & $\begin{array}{c}\mathrm{CaTiO}_{3} \\
(\mathrm{wt} \%)\end{array}$ & $\begin{array}{c}\mathrm{SrTiO}_{3} \\
(\mathrm{wt} \%)\end{array}$ & $\begin{array}{c}\mathrm{T} \text { Tolal } \\
\mathrm{wt} \%\end{array}$ \\
\hline \hline CMB base & 55 & 45 & & & & 100 \\
\hline CMB TO15 & 55 & 30 & 15 & & & 100 \\
\hline CMB TO30 & 55 & 15 & 30 & & & 100 \\
\hline CMB CTO10 & 55 & 35 & & 10 & & 100 \\
\hline CMB CTO20 & 55 & 25 & & 20 & & 100 \\
\hline CMB STO10 & 55 & 35 & & & 10 & 100 \\
\hline CMB STO20 & 55 & 25 & & & 20 & 100 \\
\hline CMB STO25 & 55 & 20 & & & 25 & 100 \\
\hline CMB STO30 & 55 & 15 & & & 30 & 100 \\
\hline CMA STO20 & 60 & 20 & & & 20 & 100 \\
\hline CMC STO20 & 49.5 & 30.5 & & & 20 & 100 \\
\hline
\end{tabular}




\subsubsection{Synthesis of $\tau_{f}$ compensating materials}

The mixture of $\mathrm{V}$-glass, $\mathrm{Al}_{2} \mathrm{O}_{3}$ and titanate was co-milled to a median particle size 2.0 to $2.2 \mu \mathrm{m}$ using $\mathrm{Al}_{2} \mathrm{O}_{3}$ media. Pellets with a diam eter $12.5 \mathrm{~mm}$ and a thickness $1 \mathrm{~mm}$ were form ed by dry pressing co-milled powder granulated with organic binder. A 2-step pr essing process was used for pellet co mpaction, which involved uniaxia 1 pressing at $43.5 \mathrm{MPa}$ followed by isostatic pressing at $206.8 \mathrm{MPa}$. The pellets were sintered at $850^{\circ} \mathrm{C}$ for $30 \mathrm{~min}$ in air. Density of all sintered materials was measured using Archim edes method. Electrodes were deposited by sputtering Au on polished sintered pellets for measurement of dielectric properties.

Pastes of selected compensating $\mathrm{m}$ aterials were made using an organic vehicle, ESL441, combined with the thinner, ESL401, (both from Electro-Science Labs) using a 3-roll mill. These pastes were screen printed on green LTCC tapes to form temperature compensation layers for SL ring resonators.

\subsection{SL Resonator Panels}

\subsubsection{Construction of panels}

Standard $254 \mu \mathrm{m}$ thick DuPont 951 LTCC tapes were used throughout this study. The conductors used include DuPont $5738 \mathrm{Au}$ for th e via fill, $5734 \mathrm{Au}$ for th e internal conductors, and $6143 \mathrm{Ag} / \mathrm{Pd}$ for the post-fired external $\mathrm{m}$ etallization. SL ring resonators having a designed base resonance of $1.5 \mathrm{GHz}$ were fabricated in 4 layer 951 panels. Figure 2 shows the LTCC tapes, before and after sintering, of a resonator layer with a printed CMB STO20 layer between the ring resonator and the 951 diel ectric. The line width of the Au ring is $0.2 \mathrm{~mm}$. The width of the printed CMB STO20 is $4 \mathrm{~mm}$. All pan els were laminated using a st andard process that included $20.7 \mathrm{MPa}$ isostatic pressing at $70^{\circ} \mathrm{C}$ for $10 \mathrm{~m}$ inutes. Panels were sintered at $850{ }^{\circ} \mathrm{C}$ for 30 min in air on $\mathrm{Al}_{2} \mathrm{O}_{3}$ setters. Sub-miniature version A (SMA) edge connectors were soldered to resonator panels to access th e embedded ring resonator for $\mathrm{f} r$ measurements. Figure 3 shows green, sintered and finished SL resonator panels with the embedded CMB STO20.

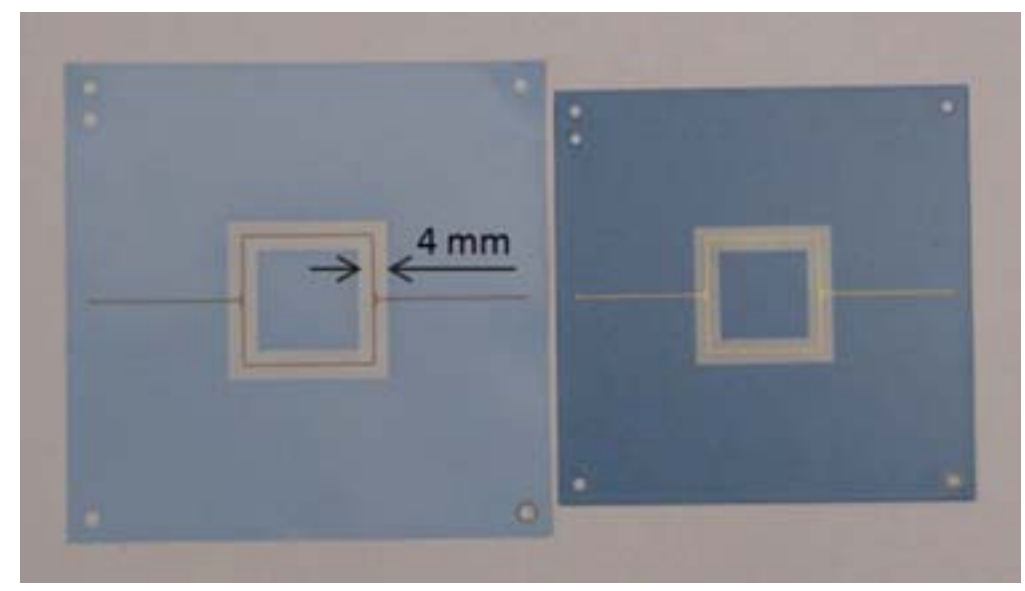

Figure 2. Au ring resonator and feed lines on $75 \times 75 \mathrm{~mm}$ green (left) and sintered (right) 951 tape with a printed STO layer in between. 

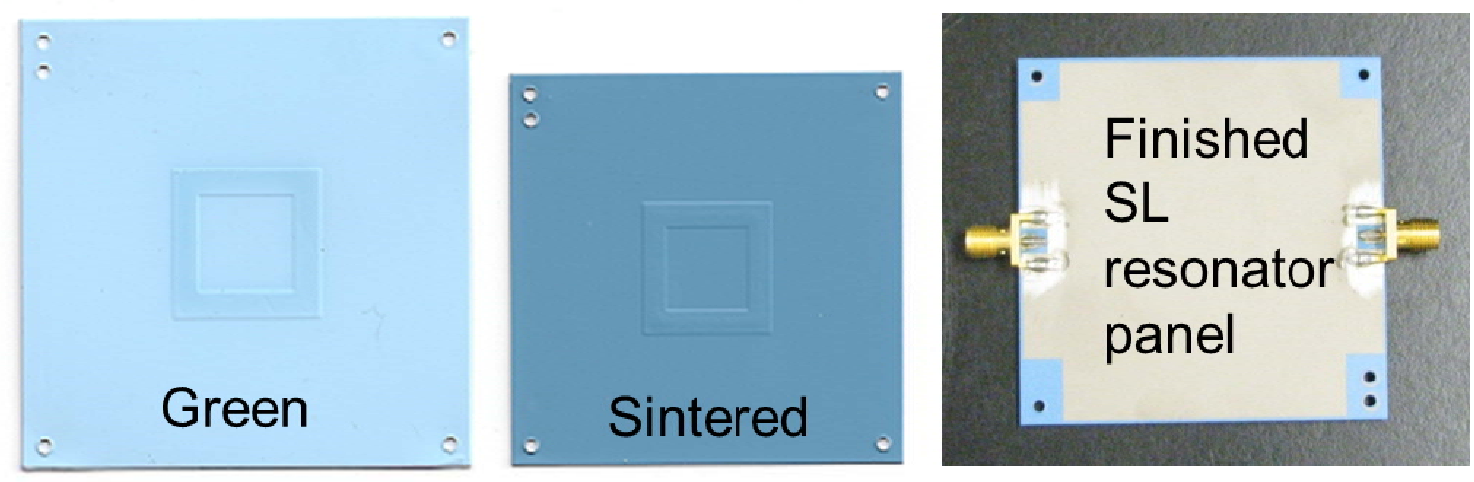

Figure 3. Green, sintered, and finished SL resonator panels.

\subsubsection{Incorporation of $\tau_{f}$ adjusters in resonator panels}

The screen printed $\tau_{\mathrm{f}}$ adjusters are in a square ring pattern. The square Au ring is $\mathrm{p}$ ositioned at the center of the $4 \mathrm{~mm}$ wide $\tau_{\mathrm{f}}$ adjusters. Using an $80 \mu \mathrm{m}$ thick $325 \mathrm{~m}$ esh screen, a typical thickness of the sintered $\tau_{\mathrm{f}}$ adjusters layer is $18 \sim 20 \mu \mathrm{m}$ from a single print, and $35 \sim 40 \mu \mathrm{m}$ from a double print using a print-dry-print pr ocess. Extra 951 tapes with the sam e printed $\tau_{f}$ adjusters were fabricated and $\mathrm{s}$ intered along with the resonator panels for measurement of the paste thickness using a Cobra laser profilometer. The measurement was taken after the paste was dried in an oven, as well as after the tapes were sintered. These tapes were also cross sectioned to examine the actual th ickness of the pastes by optical microscopy. Inspection of the $\tau_{\mathrm{f}}$ adjuster layer showed a variation in thickness, typically $\pm 3 \mu \mathrm{m}$, over the targeted thicknesses.

\subsection{Characterization}

\subsection{1. $\tau_{f}$ compensating materials}

\subsubsection{Sintering behavior}

Shrinkage data for the compensating material, in the form of a cylinder of diameter of $6.25 \mathrm{~mm}$ and thickness of $5 \mathrm{~mm}$, and the 951 dielectric, in the form of a $5 \times 5 \mathrm{~mm}$ stack of 20 layer tapes, were collected in air using a Netzsch DIL 402 dilatometer.

\subsubsection{Dielectric properties}

The capacitance of the com pensating materials was measured on sintered pellets using a HP4194A impedance analyzer at $1 \mathrm{MHz}$ over a temperature range $-50{ }^{\circ} \mathrm{C}$ to $80^{\circ} \mathrm{C}$. The capacitance of the 951 dielectric was measured on $12.75 \times 12.75 \times 0.405 \mathrm{~mm}$ coupons with sputtered Au for electrode material.

\subsubsection{Microstructure}

The crystalline phases in the $\tau_{\mathrm{f}}$ compensating materials were iden tified by X-ray dif fraction (XRD) using a Sie mens D500 diffractom eter employing a sealed tub e X-ray source (Cu K $\alpha$ 
radiation), fixed slits, a diffr acted-beam graphite m onochromator, and a scintillation detector . Typical scans were perfor med from 5 to 80 degrees $2 \theta$ using a $0.04^{\circ}$ step size at $2 \mathrm{sec} / \mathrm{step}$. Sintered microstructure was exa mined using a Zeiss Supra 55VP field em ission scanning electron microscope (SEM), where the Energy Dispersive Spectroscopy (EDS) was perform ed with a Bruker Quad SDD detector and Bruker Esprit software.

\subsubsection{SL resonator panels}

\subsubsection{Measurement of $\mathbf{f}_{\mathbf{r}}$}

The SL resonators were placed inside a temperature chamber and characterized using an Agilent E5062A network analyzer from $-50{ }^{\circ} \mathrm{C}$ to $80{ }^{\circ} \mathrm{C}$. Figure 4 shows the experi mental setup used to measure the S-param eters of a SL LTCC resona tor. The panel was h eld by the $\mathrm{m}$ easurement cables via the SMA connectors with a K-type ther mocouple attached to the surface. Prior to conducting the measurement, a standard calibration was performed on both ports of the E5062A using an A gilent calibration kit under open/sh ort/load/through conditions. The S-param eters, $\mathrm{S} 11, \mathrm{~S} 12, \mathrm{~S} 21$ and S22, were collected over a $0.3 \mathrm{GHz}$ frequency span centered at $\sim 1.5 \mathrm{GHz}$ at each temperature. The $f_{r}$ was obtained as the minim um frequency of the reflection coefficient (S11) of the ring resonator. The $\tau_{\mathrm{f}}$ of a resonator was calculated using the following equation,

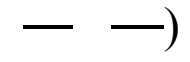

where $\mathrm{f}_{\mathrm{ro}}$ is the resonant frequency at $20{ }^{\circ} \mathrm{C}, \Delta \mathrm{f}_{\mathrm{r}}$ is the change of resonant frequency over -50 to $80^{\circ} \mathrm{C}$, and $\Delta \mathrm{T}$ equals to $130^{\circ} \mathrm{C}$.
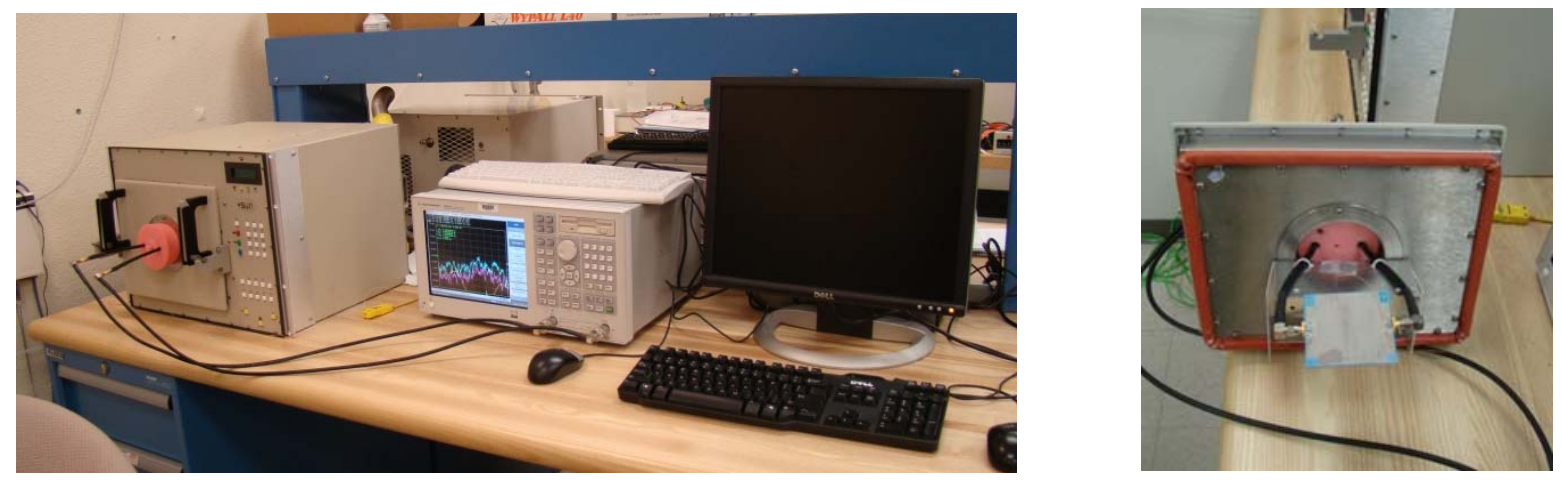

Figure 4. $f_{r}$ test setup, and the mounting of a SL resonator panel.

\subsubsection{Integrated STO layers}

Cross sections of some sintered SL resonator panels were made to inspect the cofired multilayer structure. The cross sections were exam ined by optical $\mathrm{m}$ icroscopy to $\mathrm{m}$ easure the actual thickness of the compensating material. The same cross sections were also analyzed by SEM for possible interfacial reactions between the $951 \mathrm{LTCC}$ and the compensating material. 


\section{CALCULATION OF EFFECTIVE DIELECTRIC CONSTANT AND SIMULATION OF RESONANT FREQUENCY}

An effective dielectric constant of a SL is

where $\mathrm{C}$ is the total $\mathrm{SL}$ capacitance, and $\mathrm{C}_{\mathrm{o}}$ is the total SL capacitance in air. Using a variational method [13], C can be expressed as

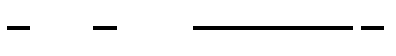

where

(5)

is the Fourier transform of the charge density distribution $\mathrm{f}(\mathrm{x}), \beta$ is the propagation constant, $\mathrm{Q}$ is the total SL charge, $w$ is the strip width, and Y is the admittance from the SL.

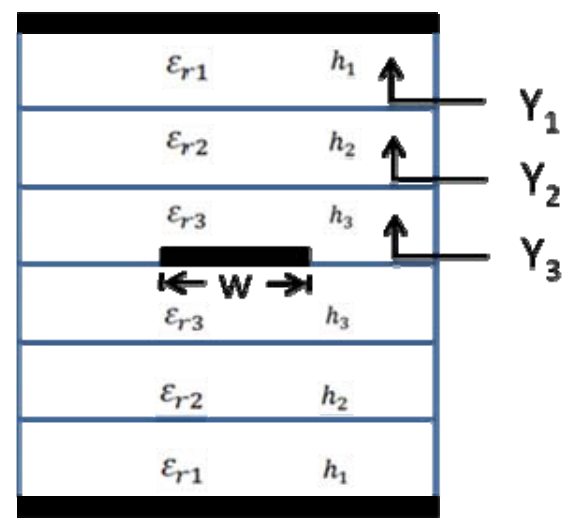

Figure 5. Admittance from dielectric interfaces.

A schematic cross section of a four tape LTCC structure with embedded SL and $\tau_{\mathrm{f}}$ compensating materials is illustrated in Figure 5. The SL is sandwiched between symmetrical three layers of dielectrics, with a dielectric constant of $\varepsilon_{\mathrm{r} 1}, \varepsilon_{\mathrm{r} 2}$ and $\varepsilon_{\mathrm{r} 3}$, and a corresponding layer thickness of $\mathrm{h}_{1}$, $h_{2}$ and $h_{3}$. The surfaces are designated as the ground planes.

$\mathrm{Y}_{1}, \mathrm{Y}_{2}, \mathrm{Y}_{3}$ are the transverse transmission line admittances between the dielectric interfaces and the ground plane. The admittance can be expressed for each successive layer $[15,16]$ as, 


$$
\begin{aligned}
& Y_{2}=\varepsilon_{o} \varepsilon_{r 2} \frac{Y_{1}+\varepsilon_{o} \varepsilon_{r 2} \tanh \left(\beta h_{2}\right)}{\varepsilon_{o} \varepsilon_{r 2}+Y_{1} \tanh \left(\beta h_{2}\right)} \\
& Y_{3}=\varepsilon_{o} \varepsilon_{r 3} \frac{Y_{2}+\varepsilon_{o} \varepsilon_{r 3} \tanh \left(\beta h_{3}\right)}{\varepsilon_{o} \varepsilon_{r 3}+Y_{2} \tanh \left(\beta h_{3}\right)}
\end{aligned}
$$

At the charge plane of the SL, the total transverse admittance $Y=2 Y_{3}$,

$$
Y=2 \varepsilon_{o} \varepsilon_{r 3} \frac{Y_{2}+\varepsilon_{o} \varepsilon_{r 3} \tanh \left(\beta h_{3}\right)}{\varepsilon_{o} \varepsilon_{r 3}+Y_{2} \tanh \left(\beta h_{3}\right)}
$$

For an air filled SL, the total capacitance is

$$
\frac{1}{C_{o}}=\frac{1}{\pi} \int_{0}^{\infty} \frac{\left[\frac{\widetilde{f}(\beta)}{Q}\right]^{2}}{\beta} \frac{1}{Y_{O}} d \beta
$$

The transverse transmission line admittance reduces to

$$
Y_{30}=\varepsilon_{o} \operatorname{coth}\left[\beta\left(h_{1}+h_{2}+h_{3}\right)\right]
$$

The total transverse transmission line admittance at the charge plane of a SL is then,

$$
Y_{o}=2 Y_{30}=2 \varepsilon_{o} \operatorname{coth}\left[\beta\left(h_{1}+h_{2}+h_{3}\right)\right]
$$

Once all th ree dielectrics were charact erized over a tem perature range, the $\varepsilon_{\text {eff }}$ is calculated numerically at each temperature $\mathrm{u}$ sing MatLab. The $\mathrm{f}_{\mathrm{r}}$ of the SL ring re sonator at a given temperature was simulated using $\varepsilon_{\text {eff }}$ and the Method of Mom entum. Finally, a curve of $\mathrm{f}_{\mathrm{r}}$ versus temperature was constructed, from which the $\tau_{\mathrm{f}}$ was calculated using equation (2). 


\section{RESULTS AND DISCUSSION}

\section{1. $\tau_{\mathrm{f}}$ Compensating Materials}

\subsubsection{Dielectric properties}

Table 3 shows the dielectric constant, $\varepsilon$, of each composition at $-50{ }^{\circ} \mathrm{C},-20^{\circ} \mathrm{C}, 0{ }^{\circ} \mathrm{C}, 20^{\circ} \mathrm{C}, 50^{\circ} \mathrm{C}$ and $80^{\circ} \mathrm{C}$. The sintered density of compensating material, the $\varepsilon$ at $20^{\circ} \mathrm{C}$, the $\tau_{\varepsilon}$ of compensating material, and an estimated $\tau_{\mathrm{f}}$ (assuming a $\alpha \sim 6 \mathrm{ppm} /{ }^{\circ} \mathrm{C}$ for all the STO compositions, and using equation (2)) are listed in Table 4 for each composition. Both CMB TO10 and CMB TO30 showed a lack of adequate densification, so these compositions were dropped from further study. Note that the estimated $\tau_{\mathrm{f}}$ of $951 \mathrm{LTCC}$ is $-59 \mathrm{ppm} /{ }^{\circ} \mathrm{C}$, lower than the $-69 \mathrm{ppm} /{ }^{\circ} \mathrm{C}$ (Figure 1) measured for a SL resonator in a 951 panel. The source of the discrepancy was unclear but $\mathrm{m}$ ay partially result from the measurement errors in sample dimension, and the determination of $\varepsilon$.

Table 3. Dielectric constant of $\tau_{\mathrm{f}}$ compensating materials from $-50^{\circ} \mathrm{C}$ to $80^{\circ} \mathrm{C}$.

\begin{tabular}{|c|c|c|c|c|c|c|c|c|c|c|}
\hline $\begin{array}{c}\text { Temp } \\
\left({ }^{\circ} \mathrm{C}\right)\end{array}$ & $\begin{array}{c}951 \\
\text { LTCC }\end{array}$ & $\begin{array}{c}\text { CMB } \\
\text { Base }\end{array}$ & $\begin{array}{c}\text { CMB } \\
\text { CTO10 }\end{array}$ & $\begin{array}{l}\text { CMB } \\
\text { CTO20 }\end{array}$ & $\begin{array}{l}\text { CMB } \\
\text { STO10 }\end{array}$ & $\begin{array}{l}\text { CMB } \\
\text { STO20 }\end{array}$ & $\begin{array}{l}\text { CMB } \\
\text { STO25 }\end{array}$ & $\begin{array}{l}\text { CMB } \\
\text { STO30 }\end{array}$ & $\begin{array}{l}\text { CMA } \\
\text { STO20 }\end{array}$ & $\begin{array}{l}\text { CMC } \\
\text { STO20 }\end{array}$ \\
\hline \hline-50 & 7.82 & 7.70 & 9.69 & 12.09 & 9.58 & 12.49 & 14.3416 .4612 .2212 .49 & \\
\hline-20 & 7.84 & 7.74 & 9.70 & 12.04 & 9.57 & 12.35 & 14.1216 .1012 .0912 .37 & \\
\hline 0 & 7.86 & 7.76 & 9.72 & 12.02 & 9.57 & 12.28 & 13.9915 .9212 .0212 .32 & \\
\hline 20 & 7.88 & 7.79 & 9.73 & 12.00 & 9.57 & 12.22 & 13.8815 .7611 .9612 .27 & \\
\hline 50 & 7.90 & 7.83 & 9.76 & 11.98 & 9.57 & 12.15 & 13.7515 .5711 .8912 .21 & \\
\hline 80 & 7.93 & 7.89 & 9.80 & 12.00 & 9.59 & 12.10 & 13.6615 .3911 .8512 .18 & \\
\hline
\end{tabular}

Table 4. Density, room temperature dielectric constant $\varepsilon, \tau_{\varepsilon}$, and estimated $\tau_{f}$ of compensating materials.

\begin{tabular}{|l|c|c|c|c|}
\hline \multicolumn{1}{|c|}{ Sample } & $\begin{array}{c}\text { Archimedes bulk } \\
\text { density }(\mathrm{g} / \mathrm{cc})\end{array}$ & $\begin{array}{c}\varepsilon \\
(1 \mathrm{MHz} \text { at RT })\end{array}$ & $\tau_{\varepsilon}\left(\mathrm{ppm} /{ }^{\circ} \mathrm{C}\right)$ & $\begin{array}{c}\text { Estimated } \tau_{\mathrm{f}} \\
\left(\mathrm{ppm} /{ }^{\circ} \mathrm{C}\right)\end{array}$ \\
\hline 951 LTCC & 3.10 & 7.88 & 112 & -59 \\
\hline CMB base & 3.19 & 7.79 & 190 & -99 \\
\hline CMB TO10 & N/A & & & \\
\hline CMB TO30 & 2.77 & & & \\
\hline CMB CTO10 & 3.20 & 9.72 & 83 & -45 \\
\hline CMB CTO20 & 3.15 & 12.0 & -58 & 26 \\
\hline CMB STO10 & 3.21 & 9.57 & 10 & -9 \\
\hline CMB STO20 & 3.30 & 12.22 & -240 & 117 \\
\hline CMB STO25 & 3.31 & 13.88 & -379 & 186 \\
\hline CMB STO30 & 3.35 & 15.76 & -525 & 259 \\
\hline CMA STO20 & 3.23 & 11.96 & -241 & 117 \\
\hline CMC STO20 & 3.35 & 12.27 & -192 & 93 \\
\hline
\end{tabular}


It should be noted that the addition of titanates to the base $\mathrm{V}$-glass $+\mathrm{Al}_{2} \mathrm{O}_{3}$ glass ceramics does result in higher dielectric constants. The higher dielectric constant is expected to decrease the $f_{r}$ of a SL resonator when the cofired compensating material is integrated into the LTCC.

\subsubsection{Chemistry}

XRD patterns of the base diele ctric and the two $\mathrm{SrTiO}_{3}$ modified compensating materials CMB STO10 and CMB STO2 0 are shown in Fi gure 6. It is evident that $\mathrm{Al}_{2} \mathrm{O}_{3}$ is the main crystalline phase in the base die lectric, with the am orphous background between $2 \theta$ value of 20 to 35 degrees representing the $\mathrm{V}$-glass. There is also a minor amount of anorthite, $\mathrm{CaAl}_{2} \mathrm{Si}_{2} \mathrm{O}_{8}$, in the base dielectric, presumably derived from the reaction between $\mathrm{Al}_{2} \mathrm{O}_{3}$ and the $\mathrm{V}$-glass. For CMB STO10, the major crystalline phases are $\mathrm{Al}_{2} \mathrm{O}_{3}$ and $\mathrm{SrTiO}_{3}$, with a m inor anorthite phase. As expected in CMB STO20, the $\mathrm{SrTiO}_{3}$ peaks grow much stronger relative to the $\mathrm{Al}_{2} \mathrm{O}_{3}$ peaks. The anorthite phase nearly disappears in CMB STO 20, indicating a suppressi on of the interaction between $\mathrm{Al}_{2} \mathrm{O}_{3}$ and the $\mathrm{V}$-glass. For both $\mathrm{S} \mathrm{TO} 10$ and $\mathrm{STO} 20$, there is no indication of compounds forming from a glass- $\mathrm{SrTiO}_{3}$ interaction. This absence of interaction is beneficial to the sintering of $\mathrm{SrTiO}_{3}$ modified compensating $\mathrm{m}$ aterials since the densification is a relatively simple viscous sintering of a glass-ceram ic body. It has been shown that crystallization during sintering of a glass -ceramic composite, either self-derived from the gla ss, or reaction-derived from glass-ceramic interaction, can significantly impede the densification process [18, 19].

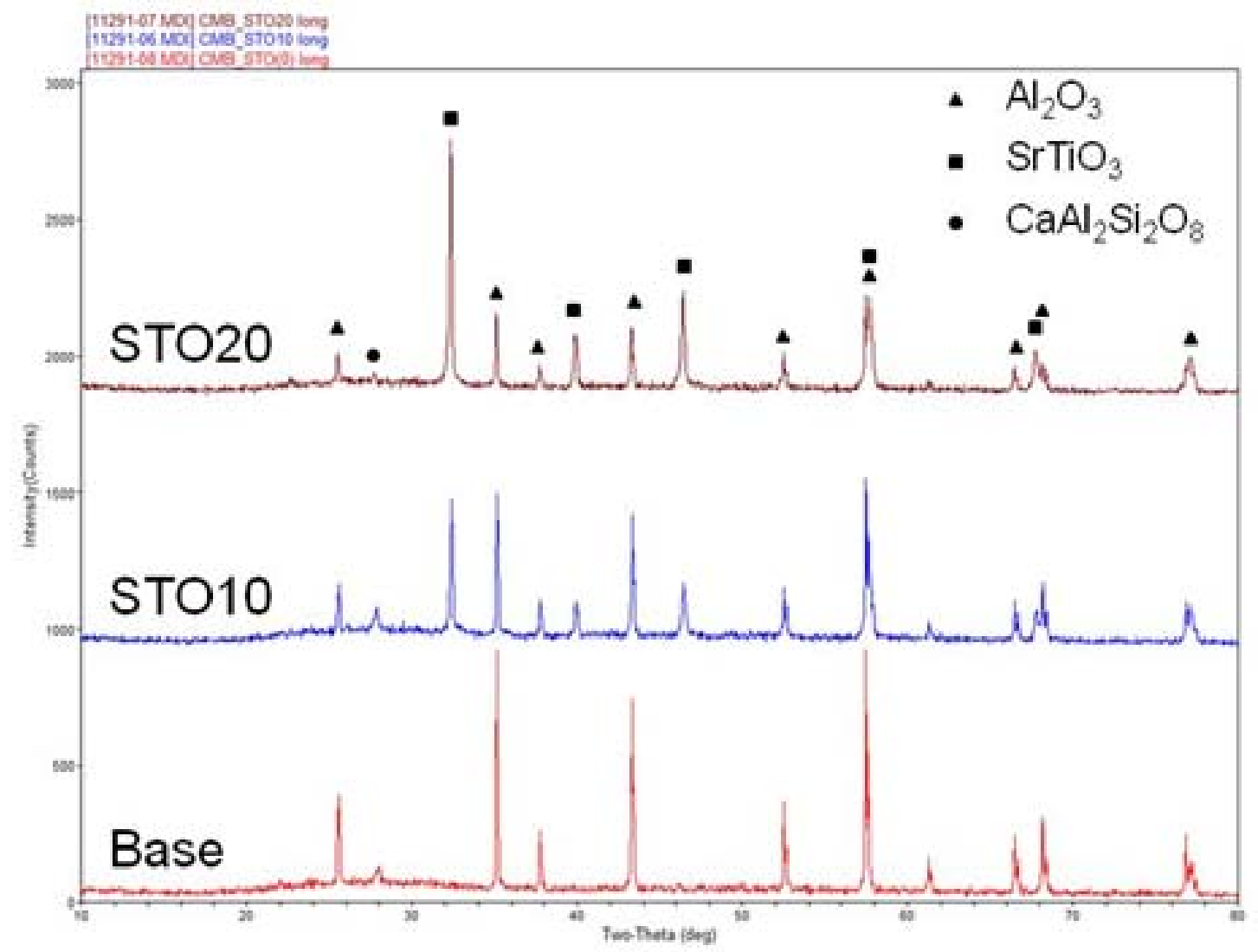

Figure 6. XRD of sintered compensating materials, STO10 and STO20, compared to the base dielectric. 


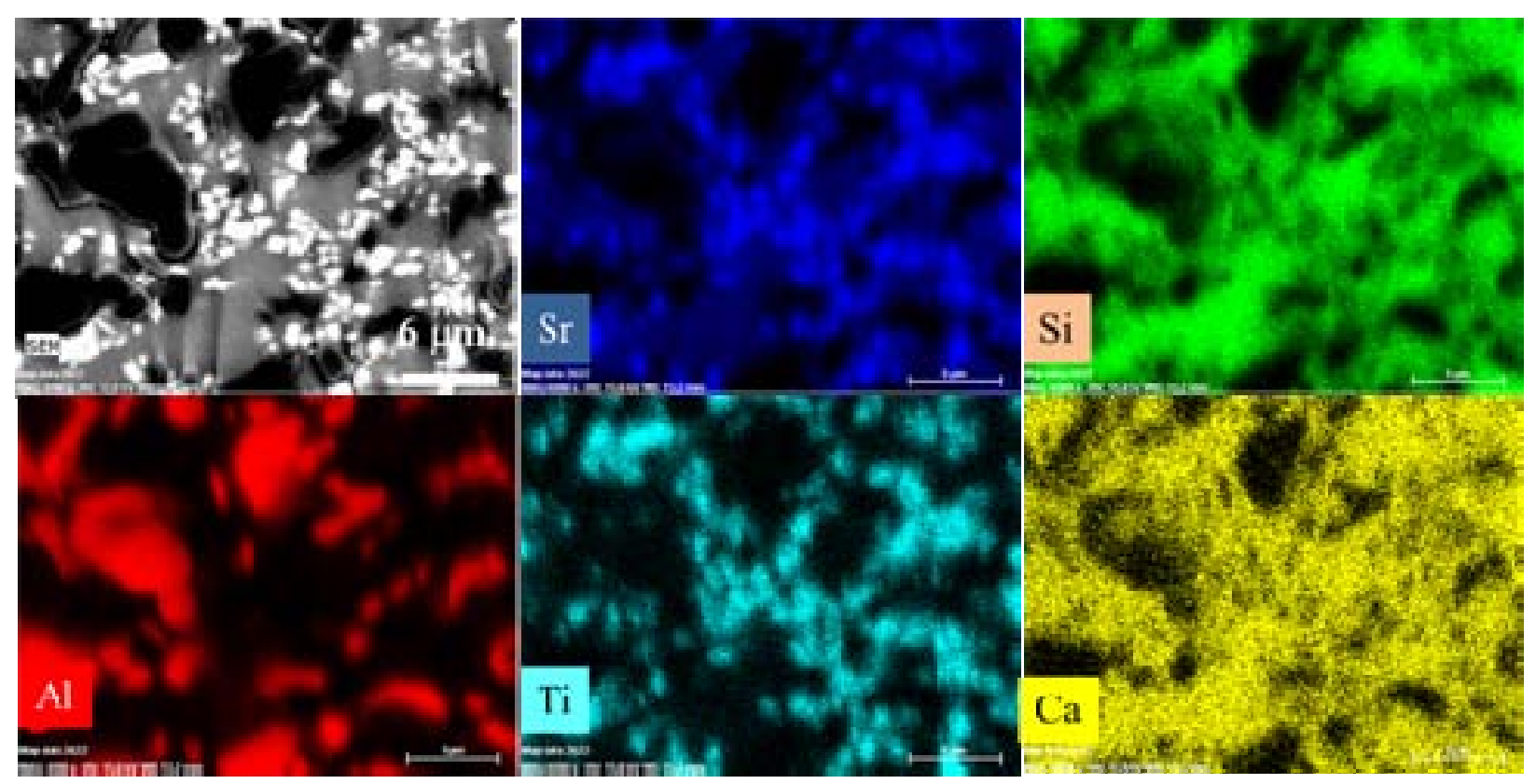

Figure 7. SEM image and element mapping of STO20.

The lack of interaction between the ceramic particles, $\mathrm{Al}_{2} \mathrm{O}_{3}$ and $\mathrm{SrTiO}_{3}$, and the $\mathrm{V}$-glass is further validated by SEM observations. Figure 7 shows a SEM image of a polished CMB STO20 surface along with elemental maps of $\mathrm{Al}, \mathrm{Sr}, \mathrm{Ti}, \mathrm{Si}$ and $\mathrm{Ca}$. The microstructure has three distinct phases, the fine $\mathrm{SrTiO}_{3}$ particles (in white), the relatively coarse $\mathrm{Al}_{2} \mathrm{O}_{3}$ particles (in black), and a continuous glass phase (in grey). The clean boundaries of $\mathrm{SrTiO}_{3}$ and $\mathrm{Al}_{2} \mathrm{O}_{3}$ particles suggest that there is no, or a minimal if any, reaction between these ceramic particles and the surrounding $\mathrm{V}$-glass. There is also $\mathrm{m}$ inimum amount of porosity in the $\mathrm{m}$ icrostructure, indicating a highly densified glass-ceramic body. This result is consistent with the measure density of $3.30 \mathrm{~g} / \mathrm{cm}^{3}$ for CMB STO20 (see Table 4).

\section{2. $\tau_{\mathrm{f}}$ Compensating Materials and 951 LTCC}

There are several progressive levels of requirements to successfully synthesis $\tau_{\mathrm{f}}$ compensating materials: 1) the materials should have large enough $\tau_{\mathrm{f}}$ that is opposite to that of 951 LTCC fo $\mathrm{r}$ effective compensation, 2) the materials should have a shrinkage and shrinkage rate that closely match to the 951 LTCC to avoid warping of the cofi red structures, and 3) there should be either least, or ideally no, chem ical reactions or inter-diffusion between the $\tau_{\mathrm{f}}$ compensating materials and the $951 \mathrm{LTCC}$ to preserve the $\tau_{\mathrm{f}}$ compensation properties.

\subsubsection{Physical compatibility}

Figure 8 plots the shrinkage curves of CM B STO20 and 951 in the Z-direction (through the thickness of the tape) for a heating rate of $5{ }^{\circ} \mathrm{C} / \mathrm{m}$ in from 500 to $850{ }^{\circ} \mathrm{C}$. The onset tem perature for shrinkage of CMB STO20, $\mathrm{m}$ easured from a shrinkage-versus-temperature plot, is $741{ }^{\circ} \mathrm{C}$. Among all of the LT CC glasses evaluated, the onset tem perature of V-glass based STO 
composition represents the closest $m$ atch to the onset temperature of $766^{\circ} \mathrm{C}$ for the $951 \mathrm{LTCC}$. In addition, the shrinkage rates of the two materials, represented by the slopes of the shrinkage curves during the temperature ramp up period, track closely to each other. The proximity of these onset temperatures and shrinkage rates provid es a solid physical basis for successfu lly cofring CMB STO20 with 951 LTCC.

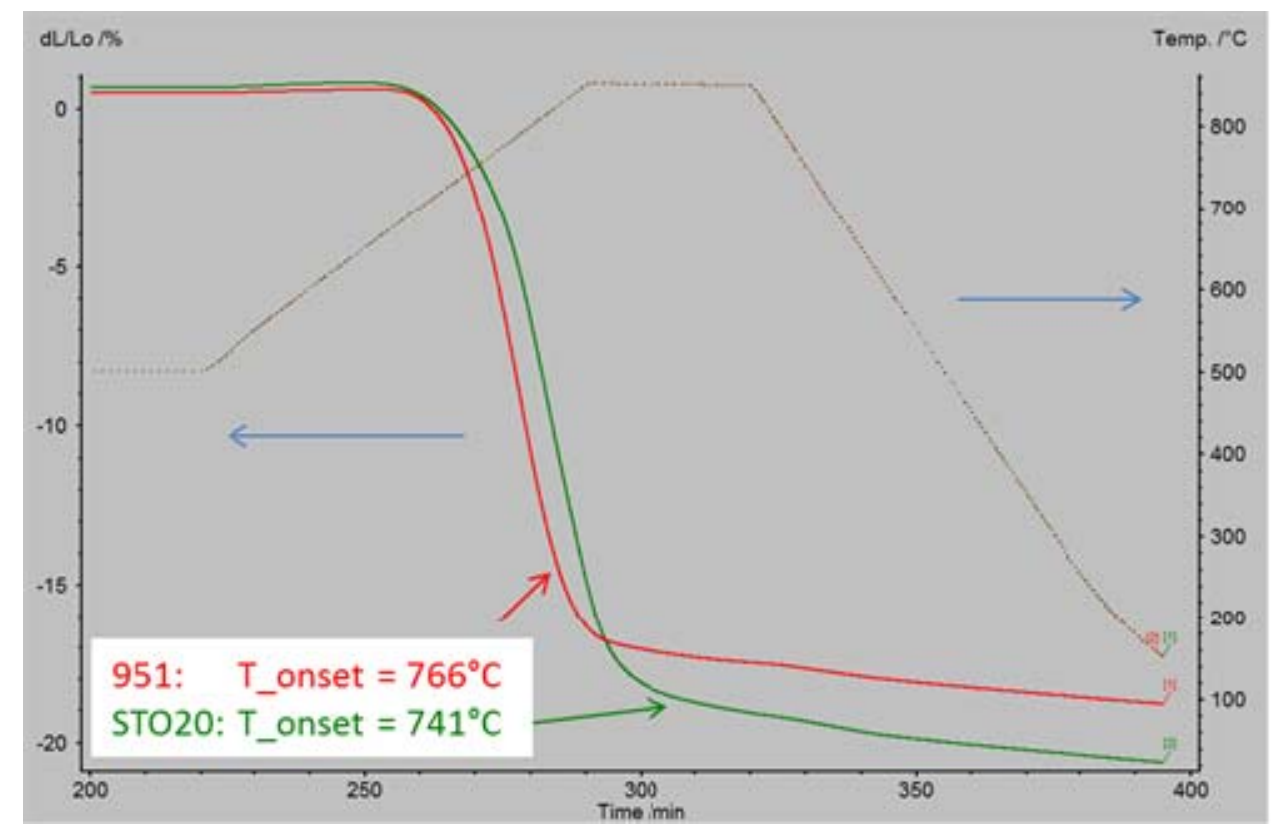

Figure 8. Shrinkage curves and onset temperatures of CMB STO20 and 951 LTCC.

\subsubsection{Chemical compatibility}

To verify the cofireability of CM B STO20 with the 951 tape, a square ring pattern of STO20 paste was screen printed onto a $75 \times 75 \mathrm{~mm} 951$ single tape and sintered using a norm al profile (similar to Figure 2 without the Au conductor). Figure 9a shows an optical im age of a fractured cross section of the cofired structure. No defo rmation in either the 951 or the CM B STO20 is visible, indicating well-matched sintering. A close look at the STO20-951 interface by SEM i s also presented in Figure 9b. A relatively clean in terface exists between the two cofired materials, suggesting no or minimal chemical interaction and/or inter-diffusion between the two materials.
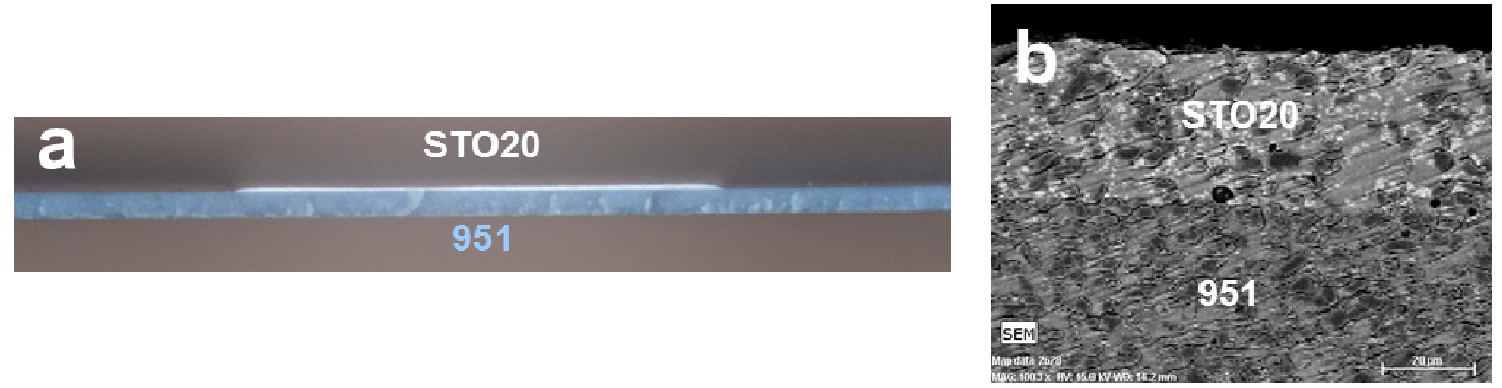

Figure 9. a) Optical cross section of sintered CMB STO20 on 951, and b) a SEM cross section of the interface between the CMB STO20 and the 951 LTCC. 

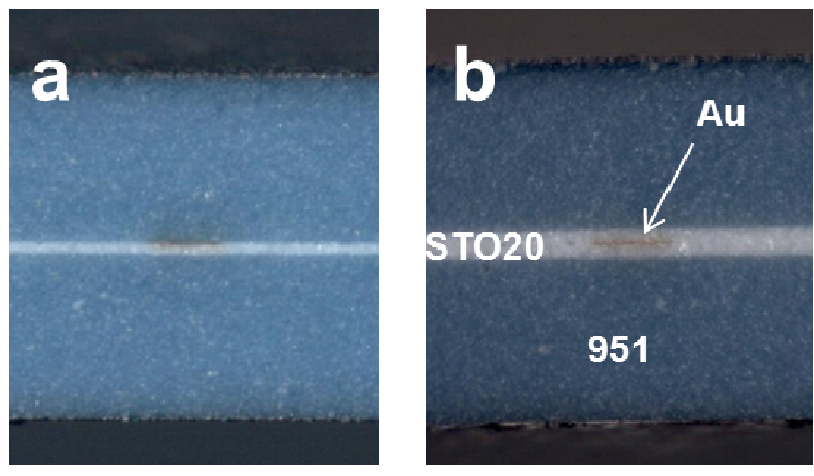

Figure 10. Embedded CMB STO20 in a 4 layer 951 LTCC, a) one side, and b) both sides of the Au conductor.

To further analyze the interfaces of embedded $\tau_{\mathrm{f}}$ compensating material in the 951 LTCC, SL resonator panels with CMB STO20 were cross sectioned for both optical and SEM exam ination. Figure 10 is an optical image of CMB STO20 cofired in a 4 layer 951 LTCC shown, a) one side, and $b$ ) both sides of the Au conductor. The hybrid multilayer panel confired nicely without any noticeable warping of the structure or delamination at the interfaces.

The cross section was further exam ined by SEM. Figures 11a and $11 \mathrm{~b}$ show an image of a Au line embedded in the CMB STO20 dielectric, and the corresponding Si m ap, respectively. It appears that the Au reaches nearly a full sinter ed density without noticeable g lass penetration from the surrounding CMB STO20. The s mall Si inclusion inside the Au in Figure 11b (pointed at with an arrow) may be attributed to the minor amount of glass frit in the $5734 \mathrm{Au}$ paste used to match the shrinkage to that of the 951 LTCC.
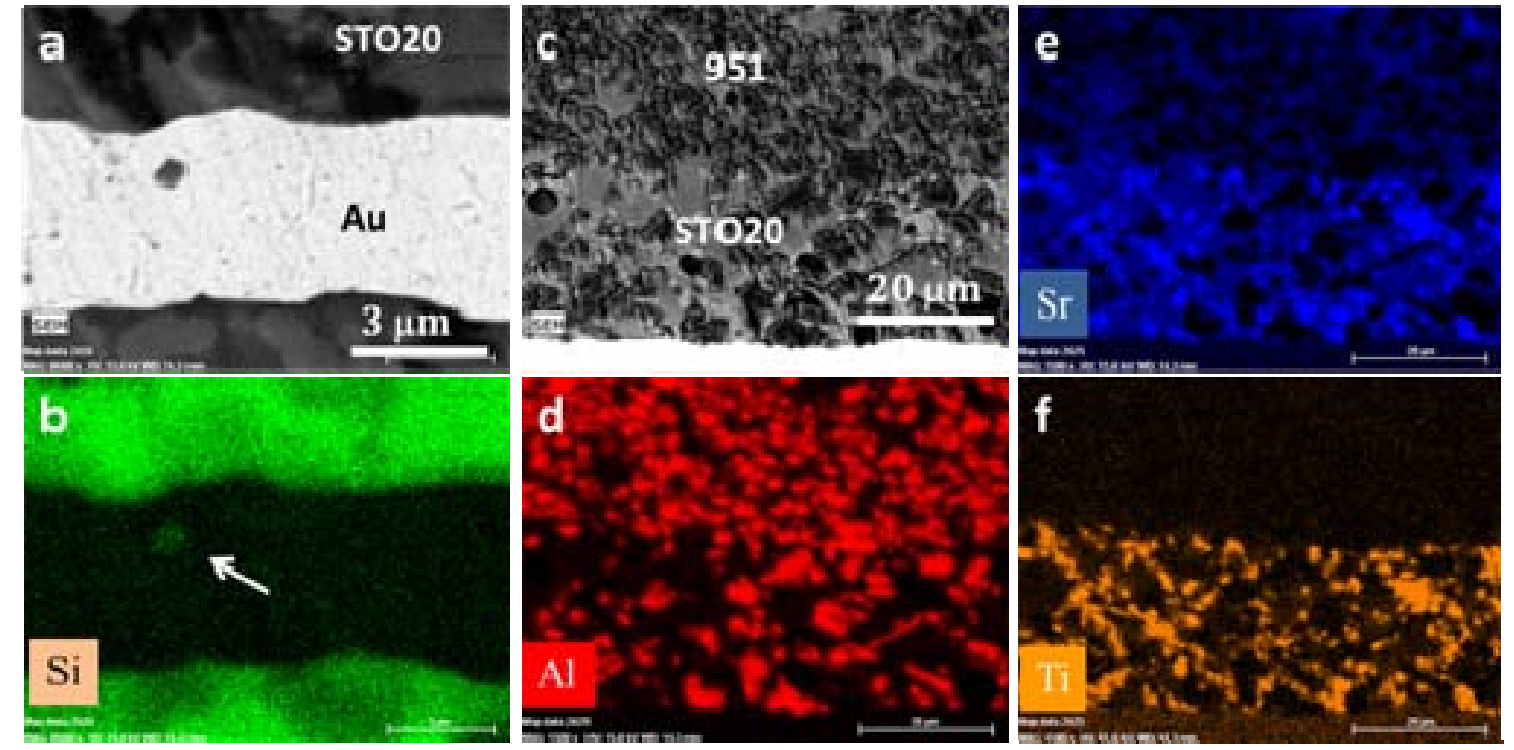

Figure 11. a) SEM cross-section image of cofired STO20 dielectric and Au resonator line; b) mapping of Si element in a); c) SEM image of embedded STO20 in 951 LTCC. The correspondent element maps for $\mathrm{Al}, \mathrm{Sr}$ and $\mathrm{Ti}$ are shown in d), e) and f). 
Figure 11c shows a well-defined boundary betw een the 951 and the CMB STO20 in the cofired structure despite the obvious difference in the volume density and the size of $\mathrm{Al}_{2} \mathrm{O}_{3}$ particles in the two materials observed in figure $11 \mathrm{~d}$. The boundary is very di stinct in the Ti mapping shown in Figure 11f, where Ti only exists in the CMB STO20 but not in the 951. Again the SEM analysis indicates that CMB STO2 0 can be cofired with 951 LTCC without noticeable interdiffusion between the two.

\section{3. $\tau_{\mathrm{f}}$ Compensation}

In this section the effects of temperature compensation are examined from different perspectives. Initially, the estimated $\tau_{\mathrm{f}}$ of each co mpensating material was used to judge whet her it provided adequate temperature compensation. Then, SL resonators panels using selected $\tau_{\mathrm{f}}$ compensating materials were built at different layer thicknesses and configurations to study the effectiveness of the temperature compensation.

\subsubsection{Effect of titanates}

Figure 12 shows the norm alized $\varepsilon$, scaled to the $\varepsilon$ value at $20{ }^{\circ} \mathrm{C}$, for $\tau_{\mathrm{f}}$ compensating materials over the temperature range $-50{ }^{\circ} \mathrm{C}$ to $80{ }^{\circ} \mathrm{C}$. The estimated $\tau_{\mathrm{f}}$ values from $\tau_{\varepsilon}$ data are listed in the legend (from Table 4). The plot visualizes th e change in the slope as the am ount of a titanate increases in the com positions. Obviously, only th e compositions that have an opposite slope to that of 951 LTCC can be used to compensate the temperature effect.

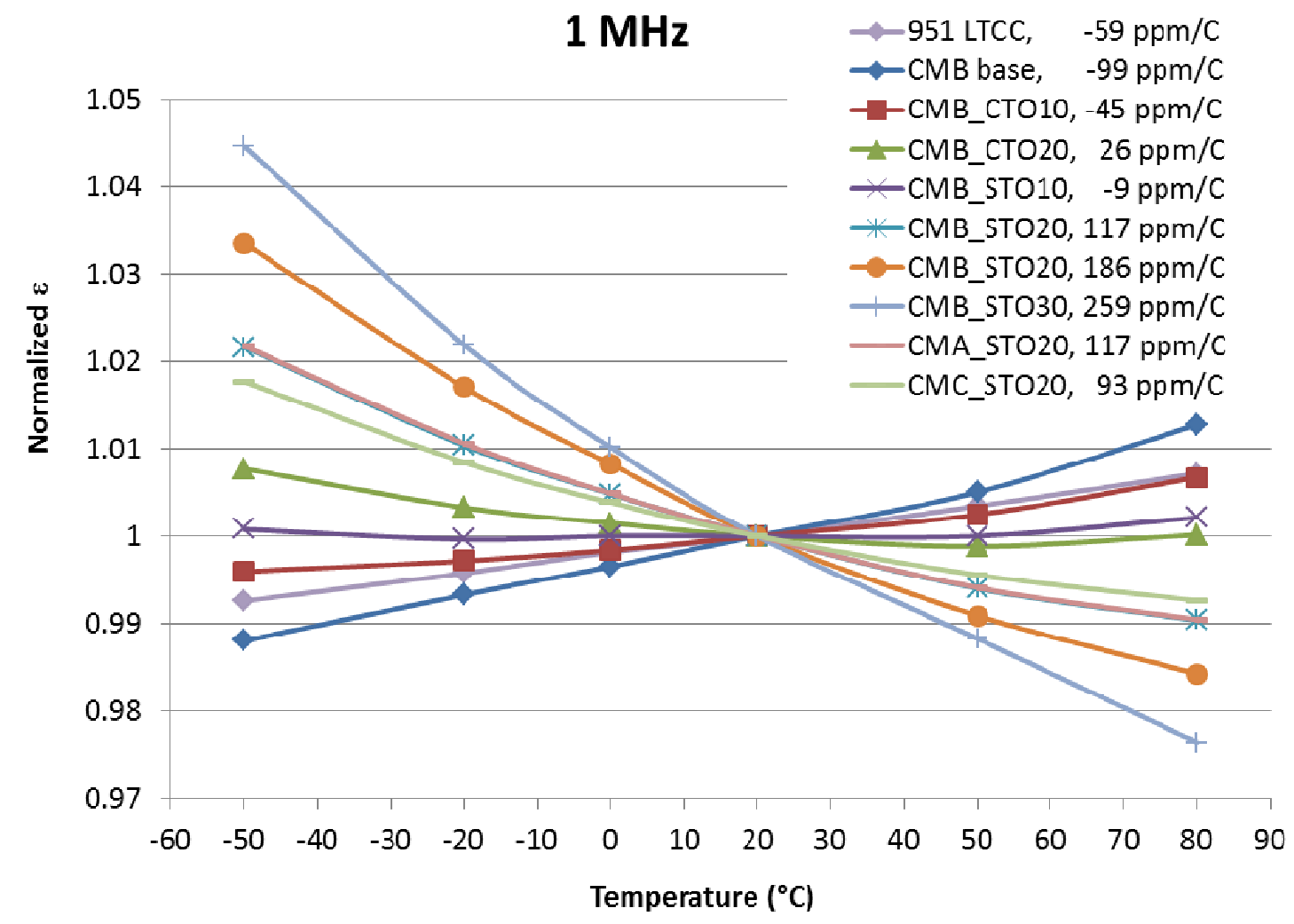

Figure 12. Tempeature dependence of normalized $\varepsilon$ of compensating materials. 
The CMB base dielectric has a $\tau_{\varepsilon}$ of $190 \mathrm{ppm} /{ }^{\circ} \mathrm{C}$, and a $\tau_{\mathrm{f}}$ of $-99 \mathrm{ppm} /{ }^{\circ} \mathrm{C}$. So, without the addition of titanates, the base dielectric has a higher $\tau_{\mathrm{f}}$ than the 951 LTCC. W ith the addition of $10 \mathrm{wt} \%$ of titanates, the CTO10 and STO10 still show positive $\tau_{\varepsilon}$, and thus negative $\tau_{\mathrm{f}}$. Obviously, the polarity of $\tau_{\mathrm{f}}$ of these two com positions is the same as that of the 951 LTCC. These compositions are not expec ted to adjust the $\tau_{\mathrm{f}}$ towards zero an $\mathrm{d}$ were eliminated from further investigation. With a higher weight pe rcentage of CTO and STO, the CMB CTO20 and CMB STO20 reach a $\tau_{\mathrm{f}}$ of $25.5 \mathrm{ppm} /{ }^{\circ} \mathrm{C}$ and $117 \mathrm{ppm} /{ }^{\circ} \mathrm{C}$, respectively. Considering that the 951 LTCC has a $\tau_{\mathrm{f}}$ of $-69 \mathrm{ppm} /{ }^{\circ} \mathrm{C}$, the CMB STO20 is ex pected to b e more effective for $\tau_{\mathrm{f}}$ compensation, and was thus down-selected for cofi ring studies, microstructure analysis, and for the fabrication of proof-of-concept SL ring resonators.

The estimated $\tau_{\mathrm{f}}$ of CMB STO25 and CMB STO30 at $180 \mathrm{ppm} \quad \quad /{ }^{\circ} \mathrm{C}$ and $259 \mathrm{ppm} \quad /{ }^{\circ} \mathrm{C}$, respectively, further increases from $117 \mathrm{ppm} /{ }^{\circ} \mathrm{C}$ for CMB STO20. Thus, it is expected that these two compositions could adjust th e $\tau_{f}$ much more effectively than CMB STO20. Both compositions were selected to be incorporated in SL resonator panels.

The $\varepsilon$ and estimated $\tau_{\mathrm{f}}$ of CMA STO20 and CMC STO20 ar e close to those of CMB STO20 (Table 3 and 4 ), sugges ting that the effect on $\tau_{\mathrm{f}}$ compensation from the amount of V-glass is much less significant com pared to the kind and the am ount of a titanate. Thus sim ilar $\tau_{\mathrm{f}}$ adjustments are expected from these three compensating formulations.

\subsubsection{Effect of glass and STO content}

SL resonator panels were $f$ abricated using STO com positions with a layer thickness of approximately $20 \mu \mathrm{m}$. Table 5 lists $\tau_{\mathrm{f}}$ data for two separate com parisons: 1) at a fixed STO20 concentration to assess the effect of glass to filler weight ratio from CMA of 60/40, CMB of $55 / 45$ to CMC of $49.5 / 50.5$, and 2) at a fixed CMB of $55 \mathrm{wt} \%$ glass to assess the effect of STO content of 20,25 and $30 \mathrm{wt} \%$.

The glass to filler ratio from CMA to CMB has a minimum impact on the temperature stability, as the $\tau_{\mathrm{f}}$ of the SL resonators are -29.5 and $-28.8 \mathrm{ppm} /{ }^{\circ} \mathrm{C}$, respectively. However the $\tau_{\mathrm{f}}$ of CMC STO20 is $-41.3 \mathrm{ppm} /{ }^{\circ} \mathrm{C}$, consistent with the estimated higher $\tau_{\mathrm{f}}$ of the CMC STO20 composition in Figure 13.

Table 5. $\tau_{\mathrm{f}}$ data for SL resonators using different STO compositions and a layer thickness of approximately $20 \mu \mathrm{m}$.

\begin{tabular}{|l|c|}
\hline $\begin{array}{c}\text { STO compositions in } \\
\text { SL resonator }\end{array}$ & $\tau_{\mathrm{f}}\left(\mathrm{ppm} /{ }^{\circ} \mathrm{C}\right)$ \\
\hline \hline CMA STO20 & -29.5 \\
\hline CMB STO20 & -28.8 \\
\hline CMB STO25 & -13.4 \\
\hline CMB STO30 & 0.5 \\
\hline CMC STO20 & -41.3 \\
\hline
\end{tabular}


The temperature stability of the resonator im proves as the $\mathrm{wt} \%$ of STO increases. The CMB STO20 with $20 \mathrm{wt} \% \mathrm{STO}$ in the composition reduces the $\tau_{\mathrm{f}}$ to $-28.8 \mathrm{ppm} /{ }^{\circ} \mathrm{C}$ from $-69 \mathrm{ppm} /{ }^{\circ} \mathrm{C}$ of the uncompensated $951 \mathrm{LTCC}$. In CMB STO25, the $\tau_{\mathrm{f}}$ is further reduced to $-13.4 \mathrm{ppm} /{ }^{\circ} \mathrm{C}$. A near zero $\tau_{\mathrm{f}}$ of $0.5 \mathrm{ppm} /{ }^{\circ} \mathrm{C}$ is achieved in CMB STO30. It is clear that the content of STO plays an important role in temperature compensation, and the most effective compensating material is the CMB STO30 which has the highest STO wt $\%$ in this study.

\subsubsection{Effect of STO layer thickness}

SL resonators made using the print-dry-print deposition of STO layers of approximately $40 \mu \mathrm{m}$ thick were also fabricated to examine the effect of STO thickness. Table 6 displays $\tau_{\mathrm{f}}$ data for resonators made using 20 and $40 \mu \mathrm{m}$ CMB STO20, CMB STO25 a nd CMB STO30 layers. For CMB STO20, the doubling of thickness from 20 to $40 \mu \mathrm{m}$ reduces the $\tau_{\mathrm{f}}$ of -28.8 to a near zero $1.9 \mathrm{ppm} /{ }^{\circ} \mathrm{C}$. The same doubling in thickness of CMB STO25, however, overcorrects the $\tau_{\mathrm{f}}$ from -13.4 to $41.2 \mathrm{ppm} /{ }^{\circ} \mathrm{C}$. It is reasonable to assume that a true zero $\tau_{\mathrm{f}}$ could be achieved with a CMB STO25 thickness between 20 and $40 \mu \mathrm{m}$. The overcorrection of $\tau_{\mathrm{f}}$ for CMB STO30 is even more pronounced, as evidenced by a $\tau_{\mathrm{f}}$ of $60.8 \mathrm{ppm} /{ }^{\circ} \mathrm{C}$ with a $40 \mu \mathrm{m}$ thick CMB STO30 versus a $\tau_{\mathrm{f}}$ of $0.5 \mathrm{ppm} /{ }^{\circ} \mathrm{C}$ at $20 \mu \mathrm{m}$.

Table 6. $\tau_{\mathrm{f}}$ data of SL resonator panels at STO thickness of 20 and $40 \mu \mathrm{m}$.

\begin{tabular}{|l|c|c|}
\hline \multirow{2}{*}{$\begin{array}{c}\text { STO compositions in } \\
\text { SL resonator }\end{array}$} & \multicolumn{2}{|c|}{$\tau_{\mathrm{f}}\left(\mathrm{ppm} /{ }^{\circ} \mathrm{C}\right)$} \\
\cline { 2 - 3 } & $20 \mu \mathrm{m}$ & $40 \mu \mathrm{m}$ \\
\hline \hline CMB STO20 & -28.8 & 1.9 \\
\hline CMB STO25 & -13.4 & 41.2 \\
\hline CMB STO30 & 0.5 & 60.8 \\
\hline
\end{tabular}

Overall the thickness of the STO layer has a significant effect on the $\tau_{\mathrm{f}}$ of the resonators. A thicker STO layer results in more temperature compensation. Data in Table 6 suggest that a zero $\tau_{\mathrm{f}}$ is readily achievable with a prop er combination of STO com position and the layer thickness. The results bring in design flex ibility and paths for process opt imization. For exam ple, if a minimum amount of compensating $m$ aterial is needed in a LTCC multilayer s tructure, then the CBM STO30 is the choice. On the other hand, if better tolerance and process consistency can be achieved using a thicker STO layer then the CMB STO20 might be used in a LTCC structure.

\subsubsection{Effect of STO configuration}

Three symmetrical configurations of STO placem ent, as shown in Figure 13, were exam ined in this study: 1) STO layers printed next to th e Au resonator ring, 2) STO layers printed 1 LTC C tape layer away from the Au ring, and 3) STO la yers printed 2 LTCC tape alyers away from the $\mathrm{Au}$ ring, i.e., just under the top and bottom ground planes. Table 7 lists the actual stack-up of dielectric layers for each STO configuration in Figure 5 for the $\varepsilon_{\text {eff }}$ calculation. 


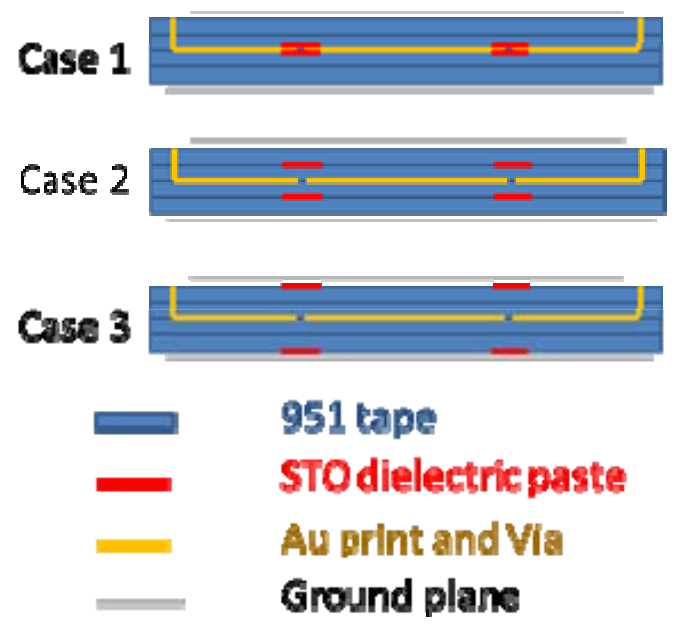

Figure 13. Three configurations of printed STO layers examined.

Table 7. Dielectric layer in the three configurations used in this study.

\begin{tabular}{|c|c|c|c|}
\hline Configuration & $\varepsilon_{\mathrm{r} 1}$ & $\varepsilon_{\mathrm{r} 2}$ & $\varepsilon_{\mathrm{r} 3}$ \\
\hline Case 1 & STO & 951 & 951 \\
\hline Case 2 & 951 & STO & 951 \\
\hline Case 3 & 951 & 951 & STO \\
\hline
\end{tabular}

The $\tau_{\mathrm{f}}$ data for multiple SL resonator panels incorporating CMB STO20 and CMB STO30 are shown in Table 8. 20 and $40 \mu \mathrm{m}$ STO layers were printed on to different LTCC tapes according to Figure 13. Resonators with $40 \mu \mathrm{m}$ CMB STO20 in cases 2 and 3 were not fabricated and measured, since it is clear from Table 8 that even resonators using $40 \mu \mathrm{m} \mathrm{CMB} \mathrm{STO30} \mathrm{are} \mathrm{far}$ from reaching a zero $\tau_{\mathrm{f}}$.

It becomes evident that, only in case 1, where the STO layers are placed next to the SL resonator, can a zero $\tau_{\mathrm{f}}$ be achieved using localized STO compensation. In case 3 , the $\tau_{\mathrm{f}}$ for a $20 \mu \mathrm{m}$ thick layer of either STO20 or STO30 is very close to the uncompensated $\tau_{\mathrm{f}}=-69 \mathrm{ppm} /{ }^{\circ} \mathrm{C}$ of the 951 LTCC. There is essentially no $\tau_{\mathrm{f}}$ adjustment. At a layer thickness $40 \mu \mathrm{m}$, the $\tau_{\mathrm{f}}$ of CMB STO30 drops only to $-62.3 \mathrm{ppm} /{ }^{\circ} \mathrm{C}$. Moving the STO la yers closer to SL in case 2 does reduce $\tau_{\mathrm{f}}$ slightly, but the $\tau_{\mathrm{f}}$ compensation is very limited, and far from reaching a true $0 \mathrm{ppm} /{ }^{\circ} \mathrm{C}$. Placing the compensating STO materials next to the SL resonator appears to be th e most effective, and may be the only practical, way to achieve $\tau_{\mathrm{f}}$ compensation.

Table 8. $\tau_{f}$ of SL resonators with different STO layer thicknesses and configurations.

\begin{tabular}{|c|c|c|c|c|}
\hline Composition & $\begin{array}{c}\text { STO thickness } \\
(\mu \mathrm{m})\end{array}$ & Case 1 & Case 2 & Case 3 \\
\cline { 3 - 5 } & 20 & -28.8 & -67.5 & -71.2 \\
\hline CMB STO20 & 40 & 1.9 & & -69.3 \\
\cline { 2 - 5 } & 20 & 0.5 & -61.7 & -62.3 \\
\hline \multirow{2}{*}{ CMB STO30 } & 40 & 60.8 & -54.8 & - \\
\cline { 2 - 5 } & & & & \\
\hline
\end{tabular}




\subsection{Simulated $\tau_{\mathrm{f}}$ Results}

\subsubsection{Effect of STO composition and thickness}

For case 1 where the STO is placed next to the SL, Figure 14 shows calculated $\varepsilon_{\text {eff }}$ as a function of temperature for CMB STO20 and CMB STO30 at a thicknesses from $5 \mu \mathrm{m}$ to $50 \mu \mathrm{m}$. As the STO20 layer becomes thicker, the $\varepsilon_{\text {eff }}$ increases accordingly. At the same tim e, the slope of $\varepsilon_{\text {eff }}$ changes from positive at $5 \mu \mathrm{m}$ to nearly flat at $50 \mu \mathrm{m}$. Larger chang es in $\varepsilon_{\text {eff }}$ over the same thickness range are seen for CMB STO 30 since the CMB STO30 has a higher $\varepsilon$ to begin with. One important distinction for the $\varepsilon_{\text {eff }}$ of CMB STO30 is the change of the slope. Sim ilar to CMB STO20, the slope of $\varepsilon_{\text {eff }}$ starts as negative at $5 \mu \mathrm{m}$ layer thickness, but ends as positive at $50 \mu \mathrm{m}$. The $\varepsilon_{\text {eff }}$ is nearly flat over temperature for a $20 \mu \mathrm{m}$ layer thickness.

\section{Case 1}

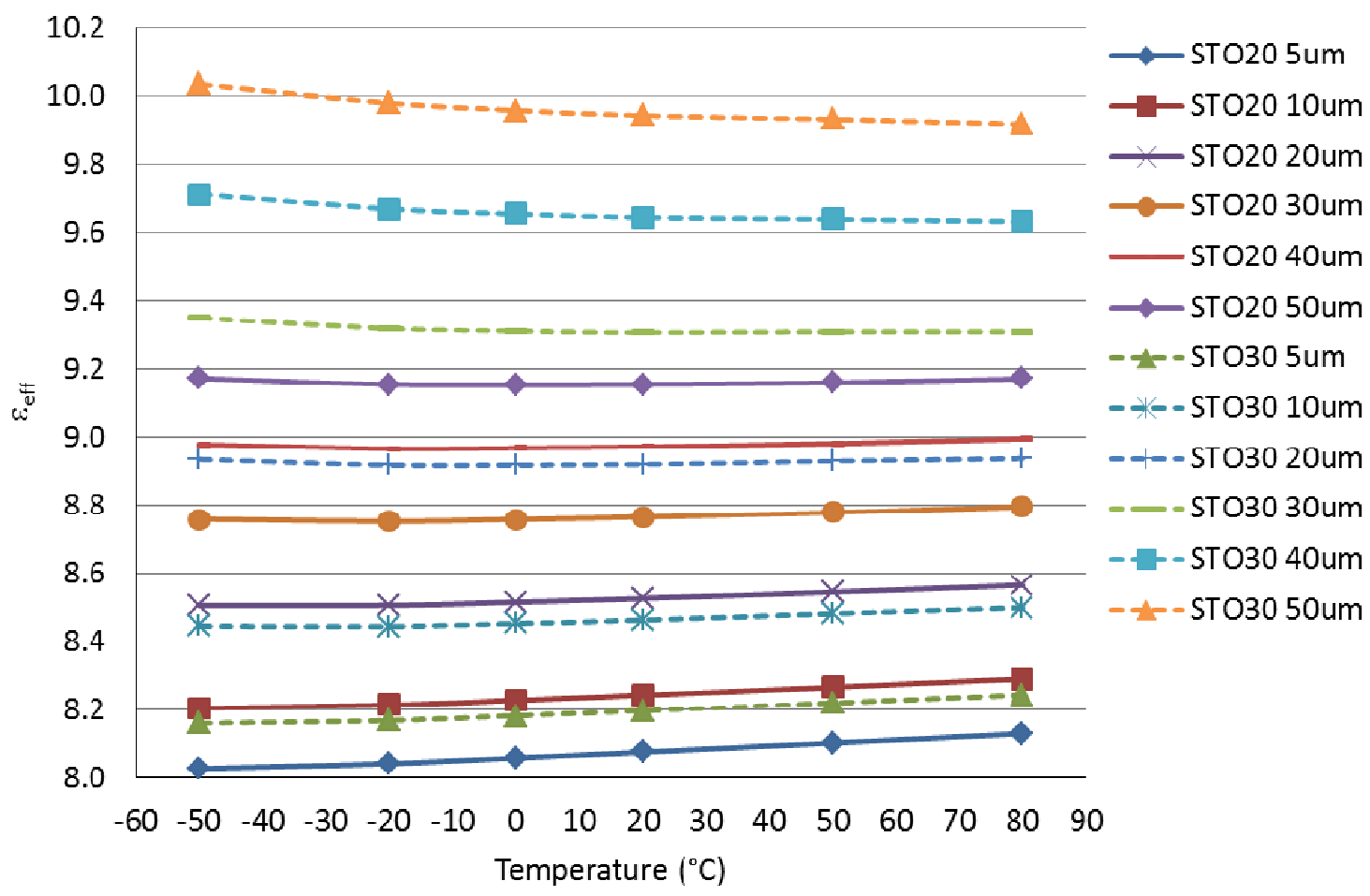

Figure 14. $\varepsilon_{\mathrm{eff}}$ of SL as a function of temperature and STO layer thicknesses from 5 to 50 $\mu \mathrm{m}$.

Figure 15 plots the simulated $f_{r}$ versus temperature for the same STOs from $5 \mu \mathrm{m}$ to $50 \mu \mathrm{m}$ thick, with the corresponding $\tau_{\mathrm{f}}$ values (slope of the $\mathrm{f}_{\mathrm{r}} \sim \mathrm{T}$ curves) shown in the legend. The sim ulated $\mathrm{f}_{\mathrm{r}}$ reflects the changes in $\varepsilon_{\text {eff: }} \mathrm{f}_{\mathrm{r}}$ decreases as $\varepsilon_{\text {eff }}$ increase, as $\mathrm{f}_{\mathrm{r}}$ correlates to $\varepsilon$ by $\mathrm{f}_{\mathrm{r}} \sim 1 /$. For CMB STO20, $\tau_{\mathrm{f}}$ decreases as the layer becomes thicker. At a thickness $20 \mu \mathrm{m}$ the simulated $\tau_{\mathrm{f}}$ is equal to $-26.9 \mathrm{ppm} /{ }^{\circ} \mathrm{C}$, which is very close to the $-28.8 \mathrm{ppm} /{ }^{\circ} \mathrm{C}$ measured from the SL resonator (Table 6). The simulated $\tau_{\mathrm{f}}$ reaches $0.5 \mathrm{ppm} /{ }^{\circ} \mathrm{C}$ at a thickness $50 \mu \mathrm{m}$, while the measured $\tau_{\mathrm{f}}$ is $1.9 \mathrm{ppm} /{ }^{\circ} \mathrm{C}$ at a thickness $40 \mu \mathrm{m}$, suggesting that the simulation might underestimate the $\tau_{\mathrm{f}}$ when a STO layer becomes thicker. 


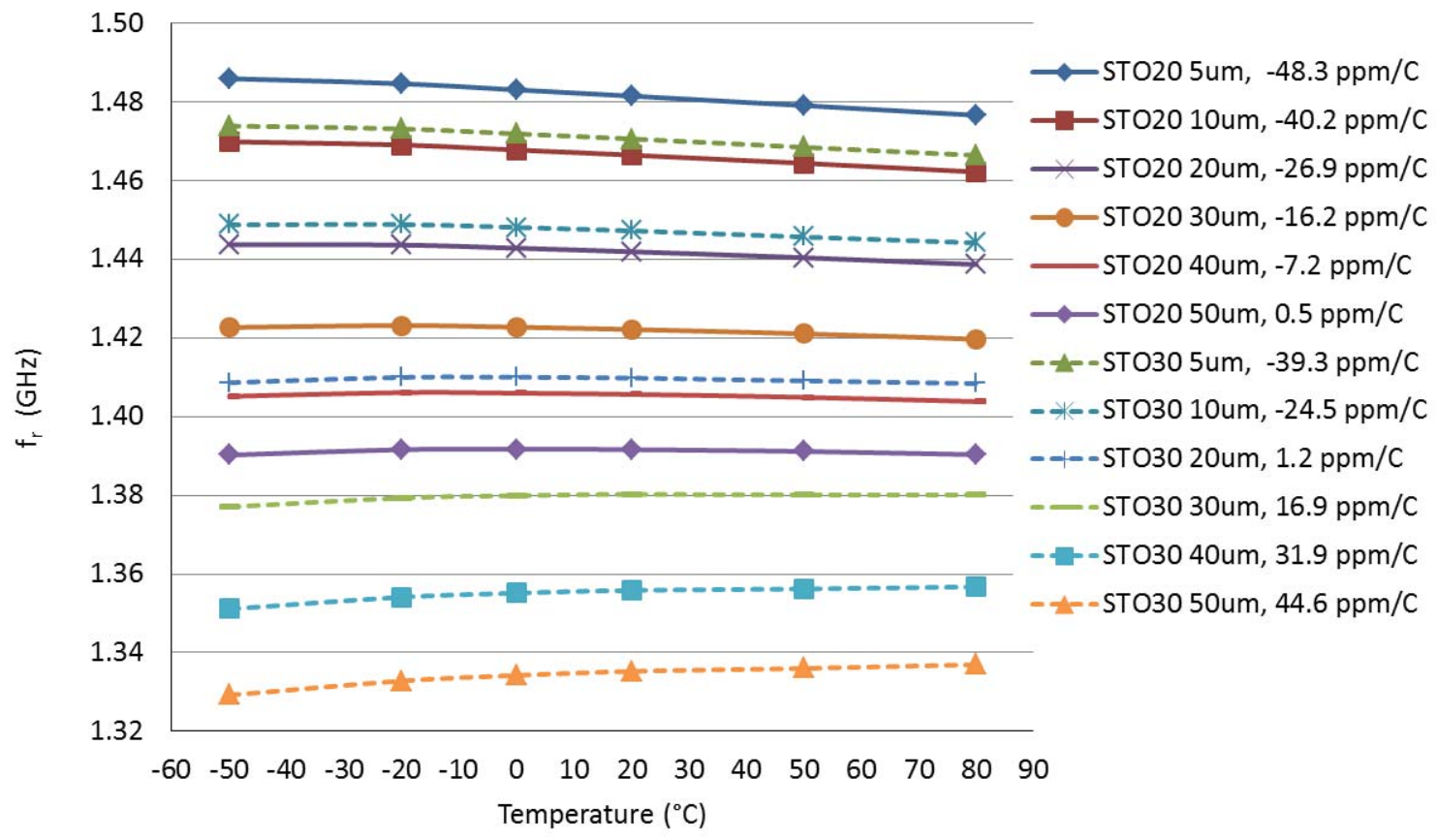

Figure 15. Simulated $f_{r}$ of SL resonators as a function of temperature at STO layer thicknesses of 5 to $50 \mu \mathrm{m} . \tau_{\mathrm{f}}$ data are shown in legend.

For CMB STO30, there is a crosso ver thickness where the $\tau_{\mathrm{f}}$ changes polarity from negative to positive as thickness increases. The crossover thickness is about $20 \mu \mathrm{m}$ where the simulated $\tau_{\mathrm{f}}$ is equal to $1.2 \mathrm{ppm} /{ }^{\circ} \mathrm{C}$. The simulation is consistent with the experim ent in which a $\tau_{\mathrm{f}}$ of 0.5 $\mathrm{ppm} /{ }^{\circ} \mathrm{C}$ is measured at $20 \mu \mathrm{m}$ (Table 6). Again, the sim ulation underestimates $\tau_{\mathrm{f}}$ at thicker STO layers, as evidenced by the simulated $\tau_{\mathrm{f}}$ of $31.9 \mathrm{ppm} /{ }^{\circ} \mathrm{C}$ versus the measured $60.8 \mathrm{ppm} /{ }^{\circ} \mathrm{C}$ at the same $40 \mu \mathrm{m}$ CMB STO30 thickness. The cause of th e underestimation is no $t$ clear at th $\mathrm{e}$ moment, and warrants further investigation.

\subsubsection{Effect of STO configurations}

Figure 16 compares the temperature and thickness dependence of $\varepsilon_{\text {eff }}$ for CMB STO30 between cases 1 and 2 . The $\varepsilon_{\text {eff }}$ is higher in case 1 . For example, at $20{ }^{\circ} \mathrm{C}$ and $5 \mu \mathrm{m}$ thick, the $\varepsilon_{\text {eff }}$ is 8.20 in case 1 , and 7.91 in case 2 , which is an increase of $\sim 3.5 \%$. Sim ilar increase in $\varepsilon_{\text {eff }}$ is observed at all temperatures and CMB STO30 thickness es for case 1. The results indicate that the SL sees more of the CMB STO30 when the $\mathrm{m}$ aterial is placed next to it, compared to the configuration where the same material is placed one LTCC tape layer away.

The relative change in $\varepsilon_{\text {eff }}$ with STO30 thickness is also more substantial in case 1. For example, at $20{ }^{\circ} \mathrm{C}$, the $\varepsilon_{\text {eff }}$ is 8.20 at $5 \mu \mathrm{m}$, and 9.94 at $50 \mu \mathrm{m}$, which is an increase of $\sim 21.2 \%$. In contrast, for case 2 , the $\varepsilon_{\text {eff }}$ is 7.91 at $5 \mu \mathrm{m}$, and 8.17 at $50 \mu \mathrm{m}$, which is an increase only of $\sim 3.3 \%$. Certainly, for $\tau_{\mathrm{f}}$ compensation by adjusting the amount of STO30, the result is more pronounced when the compensating dielectric is integrated next to the SL resonator. 


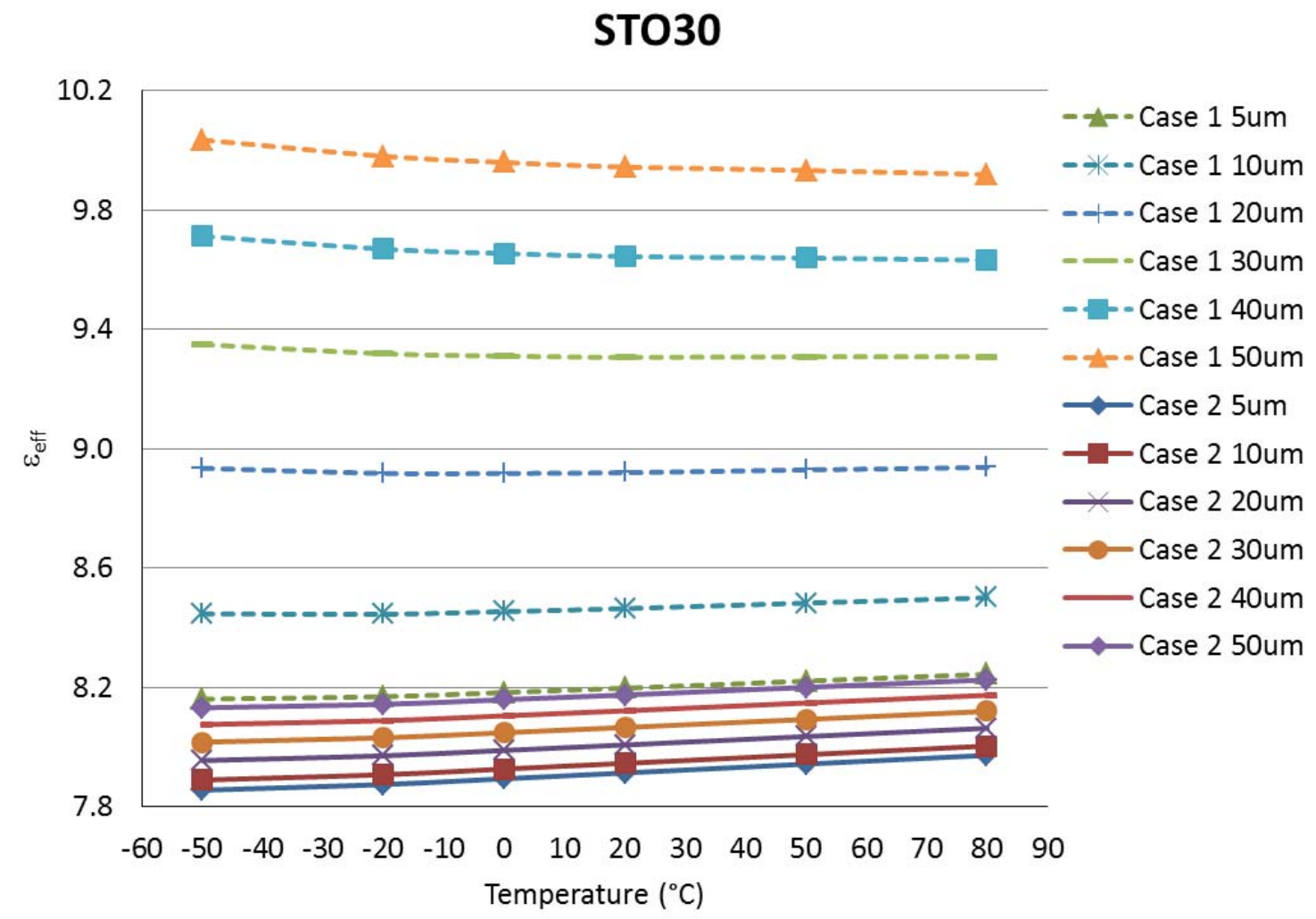

Figure 16. $\varepsilon_{\mathrm{eff}}$ of STO30 as a function of temperature for cases 1 and 2.

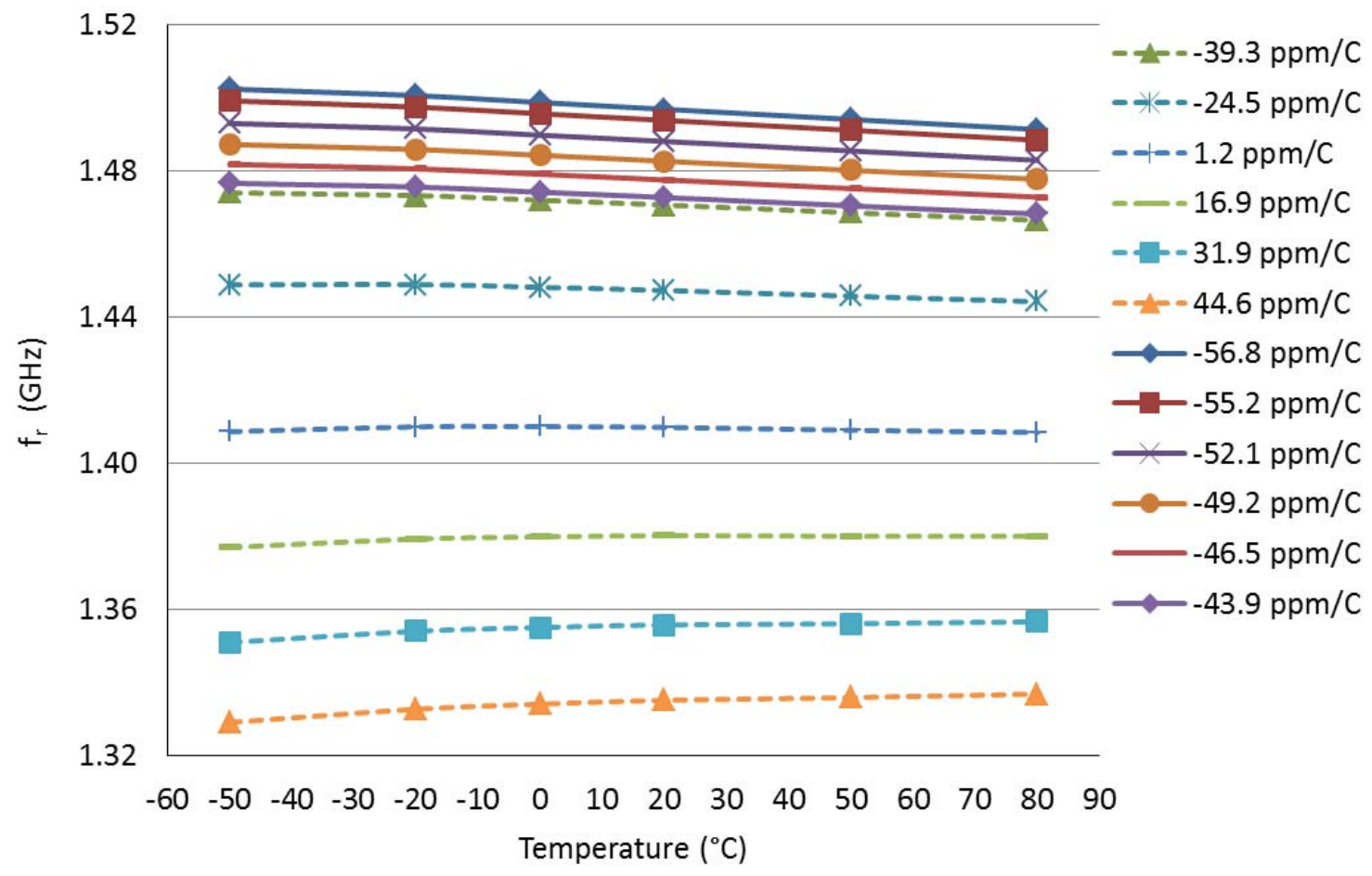

Figure 17. $f_{r}$ of STO30 as a function of temperature for cases 1 and 2. 
Both of these effects are reflected in the sim ulated $\mathrm{f}_{\mathrm{r}}$ over tem perature in Figure 17 with the corresponding $\tau_{\mathrm{f}}$ shown in the legend. For the CMB STO30 in case 1 , the $\tau_{\mathrm{f}}$ reaches $1.2 \mathrm{ppm} /{ }^{\circ} \mathrm{C}$ at a thickness of $20 \mu \mathrm{m}$. For the same thickness in case 2 , the $\tau_{\mathrm{f}}$ is calculated as $-52.1 \mathrm{ppm} /{ }^{\circ} \mathrm{C}$. In fact, in case 2 , the $\tau_{\mathrm{f}}$ does not have a crossover point wher e it changes polarity, as evidenced by the negative slope of all $\mathrm{f}_{\mathrm{r}} \sim \mathrm{T}$ curves at STO thicknesses from 5 to $50 \mu \mathrm{m}$. Rather, the $\tau_{\mathrm{f}}$ remains negative, and only drops to $-43.9 \mathrm{ppm} /{ }^{\circ} \mathrm{C}$ at a thickness $50 \mu \mathrm{m}$. In short, when placed one LTCC tape layer away from the SL resonator, the CMB STO30 does not ef fectively adjust the $\tau_{\mathrm{f}}$ of the resonator to $0 \mathrm{ppm} /{ }^{\circ} \mathrm{C}$.

Similar analysis is exten ded to CMB STO30 in case 3, where the STO layer is two LTCC tape layers away from the SL. The $\tau_{\mathrm{f}}$ compensation in this configurat ion is even less ef fective than that in cas e 2. As expected, the an alysis also shows the CMB STO20 has less effect on $\tau_{\mathrm{f}}$ adjustment than CMB STO30 for both cases 2 and 3 . The simulated $\tau_{\mathrm{f}}$ for cases 1, 2 and 3 using CMB STO20 and CMB STO30 at thicknesses of 5 to $50 \mu \mathrm{m}$ are plotted in Figure 18. It is clear that, only in case 1 , does the $\tau_{\mathrm{f}}$ reach $0 \mathrm{ppm} /{ }^{\circ} \mathrm{C}$. For both cases 2 and 3 , the effect of STO on the adjustment of $\tau_{\mathrm{f}}$ is very limited, and far from reaching $0 \mathrm{ppm} /{ }^{\circ} \mathrm{C}$, as evidenced by the clustering of $\tau_{\mathrm{f}}$ data points in a -40 and $-60 \mathrm{ppm} /{ }^{\circ} \mathrm{C}$ range. Figure 18 also includes the measured $\tau_{\mathrm{f}}$ data for case 1 . The sim ulated $\tau_{\mathrm{f}}$ fit the experimental data well at a layer th ickness of $20 \mu \mathrm{m}$ for both STOs. However, the simulation underestimates the $\tau_{\mathrm{f}}$ for the $40 \mu \mathrm{m}$ layer.

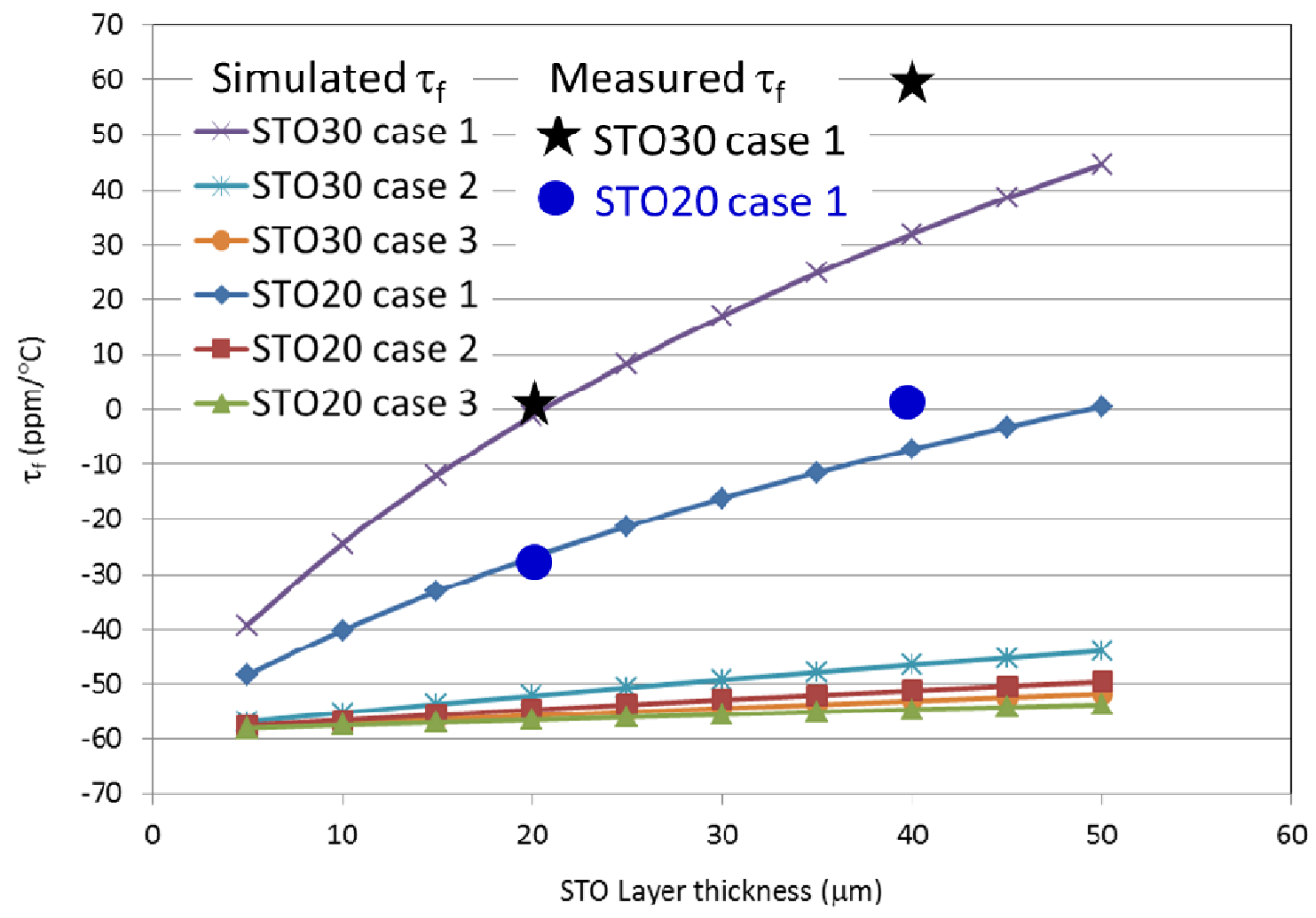

Figure 18. $\tau_{f}$ of SL resonators from simulation (solid lines) and experiment (discrete points). 


\subsection{Mechanisms of Effective $\tau_{f}$ Compensation}

In this section we try to expla in the effectiveness of $\tau_{\mathrm{f}}$ compensation in cas e 1 by addressing energy distribution in a heterogeneous dielectric multilayer structure. The discuss ion is based more on physical principles rather than detailed analytical analysis.

\subsubsection{Energy filling factor}

The overall $\tau_{\mathrm{f}}$ of a dielectric composite is given by [7]:

$$
\tau_{f}=\sum_{i} P_{i} \tau_{f i}
$$

where $\tau_{f i}$ is the temperature coefficient of resonant frequency of dielectric $\mathrm{i}$, and $\mathrm{P}$ i, the electromagnetic (EM) e nergy filling factor, which is the fraction of the total energy confined within the volume occupied by dielectric $i$. $P_{i}$ is determined by the dielectric constant, volum e, and geometry of dielectric i, as well as the EM field distribution inside the dielectric.

For a dielec tric composite with sim ple geometry, such as a cylindr ical puck with altern ating layers of two dielectrics, the calculation of $\mathrm{P}_{\mathrm{i}}$ is straight forward $[7,8]$. However, for a SL with a finite conductor width inside a $\mathrm{m}$ ultilayer dielectric, such as the in tegration of dissim ilar $\tau_{\mathrm{f}}$ compensating dielectrics in a hos t LTCC dielectric, the ca lculation of $\mathrm{P}_{\mathrm{i}}$ is complicated by the complex EM field distribution, as well as the reflection/refraction of EM waves at the dielectric interfaces.

\subsubsection{Energy concentration in STO dielectrics in case 1}

The total sintered thickness of a 4-tape $951 \mathrm{LT}$ CC panel is $0.844 \mathrm{~mm}$, resulting in a distance of $0.422 \mathrm{~mm}$ between the SL and the gr ound planes. At a line width of $0.2 \mathrm{~mm}$, the aspect ratio of the "SL capacitor" is less than $1 / 2$. Hence the electric field distribution between the SL and the ground plane is very different fr om an ideal parallel plate cap acitor (which typically has an aspect ratio $\geq 10$ ), in which the electric field is confined within the capacitor dielectric with no or minimum fringing effect. Rather, the fringing electric field of the SL in this study dom inates the field distribution.

With the STO layers next to the S L, the oblique incidence of the fringing electric field at the STO-LTCC dielectric interface follows Snell's law. Using the CMB STO30 as an exam ple, the dielectric constant $\varepsilon_{\mathrm{STO} 30}=15.76$ is twice the $\varepsilon_{\mathrm{LTCC}}=7.88$ at $20{ }^{\circ} \mathrm{C}$, so there is an existence of a critical, or total internal reflection, angle $\theta_{\mathrm{c}}$,

$$
\theta_{c}=\operatorname{asin}\left(\frac{n_{L C T T}}{n_{S T O 30}}\right)=\operatorname{asin}\left(\frac{\sqrt{\varepsilon_{L T C C}}}{\sqrt{\varepsilon_{S_{T T 30}}}}\right)=45^{\circ}
$$

where $\mathrm{n}_{\mathrm{LTCC}}$ and $\mathrm{n}_{\mathrm{STO} 0}$ are the refractive indices of the $951 \mathrm{LTCC}$ and STO30, respectively. A $t$ an incident angle lower than $\theta_{\mathrm{c}}$, part of the fringing electric is reflected back to the S TO30, and part is transmitted into the LTCC. At an incident angle higher than $\theta_{c}$, the fringing field is totally reflected back to the STO layer. The partia 1 and total reflections of the field at the S TO-LTCC interface confine a disproportionally higher amount of electric energy within the STO layers. 
According to equation (14), the higher energy filling factor, $\mathrm{P}_{\mathrm{STO}}$, amplifies the contribution from the STO, while the $r$ elatively lower $P_{\text {LTCC }}$ reduces the effect fr om the 951 LTCC. This combination results in a much more effective $\tau_{\mathrm{f}}$ compensation when a STO is placed next to the SL.

For cases 2 and 3, the oblique incidence of the fringing electric field at the LTCC-STO interface do not lead to a total reflection of the field inside the STO layers at any incident angle, since the EM waves hit the interface from the side $h$ aving a lower dielectric constant. The energy in the STO is equal to $1 / 2 \varepsilon_{\text {STO } 30} \mathrm{E}^{2} * \mathrm{~V}_{\text {STO }}$, where $\mathrm{E}$ is the electric fiel $d$ transmitted through the STO layers, and $\mathrm{V}_{\text {STO }}$ is the volume of STO. For a STO layer thickness of $40 \mu \mathrm{m}$, its volume fraction is fairly small compared to the volume of the $422 \mu \mathrm{m}$ thick LTCC. The $\tau_{\mathrm{f}}$ of the SL resonator is, thus, largely dominated by the $\tau_{\mathrm{f}}$ of the 951 LTCC. 


\section{CONCLUSIONS}

We have demonstrated that, with the design of proper $\tau_{\mathrm{f}}$ compensating materials and successful cofiring of the $m$ aterials with DuPont 951 LTCC, SL resonators having a near zero $\tau_{\mathrm{f}}$ can be produced. The compensation of the $\tau_{\mathrm{f}}$ is realized locally inside a LTCC structure where the resonators reside. Among the examined titanate materials, $\mathrm{SrTiO}_{3}$ is the best $\tau_{\mathrm{f}}$ adjuster due to its higher $\tau_{\varepsilon}$. The adjustment of $\tau_{\mathrm{f}}$ scales with the amount of a titanate in a compensating material, as well as the thickne ss of the screen printed compensating material. More im portantly, the most effective compensation of $\tau_{\mathrm{f}}$ is achieved by incorporating a give $\mathrm{n}$ compensating material next to the $\mathrm{SL}$ resonator. $\tau_{\mathrm{f}}$ compensation is diminished when the compensating material is placed away from the SL. The electric energy concentration at the compensating layers surrounding the SL is attributed to the effectiveness of the $\tau_{\mathrm{f}}$ compensation. EM simulation of $\tau_{\mathrm{f}}$ using $\varepsilon_{\text {eff }}$ calculated using a variational method confirms the experimental observation. 


\section{REFERENCES}

1. C. Wang and K. A. Zaki, "Tem perature Compensation of Combline Resonator and Filters", IEEE MMT-S Intern. Microwave Sump, Digest 3, pp 1041-1044, 1993.

2. H. Johnson and A Tunum en, "Temperature Co mpensated Dielectric Filter", U S Patent 5302924, 1994.

3. R. C. Kell, A. C. Gre enham and G. C. E. Olds, "High-P ermittivity Temperature-Stable Ceramic Dielectrics with Low Microwave Loss", J. Am. Ceram Soc, Vol 56, pp 352-354, 1973.

4. S. Kucheiko, J, Choi, H. Ki m, H. Jung, "M icrowave Dielectric Properties of CaTiO 3$\mathrm{Ca}\left(\mathrm{Al}_{1 / 2} \mathrm{Ta}_{1 / 2}\right) \mathrm{O}_{3}$ Ceramics”, J. Am. Ceram Soc., Vol 79, pp 2739-43, 1996.

5. W. Wersing, "Microwave Ceramics for Resonators and Filters", Solids State and Mat Sci, 1(5), pp 715-731, 1996.

6. I. M. Reaney and D. Iddles, "Microwave Diel ectric Ceramics for Resonators and Filte rs in Mobile Phone Networks”, J. Am. Ceram Soc., 89, pp 2063-2072, 2006.

7. N. Alford, J. Breeze, S. Penn and M. Poole, "Layered $\mathrm{Al} \quad{ }_{2} \mathrm{O}_{3}-\mathrm{TiO}_{2}$ Composite Dielectric Resonators With Tunable Temperature Coefficient for Microwave Applications", IEE ProcSci. Meas. Technol., Vol. 147, No. 6, pp 269-273, 2000.

8. L. Li and X. M. Chen, "Adhesive-Bonded $\mathrm{Ca}\left(\mathrm{Mg} \quad{ }_{1 / 3} \mathrm{Nb}_{2 / 3}\right) \mathrm{O}_{3} / \mathrm{Ba}\left(\mathrm{Zn}_{1 / 3} \mathrm{Nb}_{2 / 3}\right) \mathrm{O}_{3}$ Layered Dielectric Resonators with Tunable Te mperature Coefficient of Resonant Frequency", J. Am. Ceram. Soc., 89, pp. 544-549, 2006.

9. S. Dai, R. Huang and D. W ilcox, "Use of T itanates to Achieve a temperature $\mathrm{S}$ table Low Temperature Cofired Ceramic Dielectric for Wireless Applications", J. Am. Ceram, Soc, 85, pp 828-832, 2002.

10. H. Jantunen, "Te mperature Coefficient of Microwave Resonance Frequency of a LowTemperature Cofired Ceramic (LTCC) System”, J. Am. Ceram, Soc, 85, pp 697-699, 2002.

11. H. Kapta, T. Inoue and J. Kato, "Low Fire Bismuth Based Di electric Ceramics for Microwave Use”, Jpn. J. Appl. Phy., 31, pp 3152-55, 1992.

12. Y. Choi, J. Park, J. G. Park, "M iddle-permittivity LTCC Dielectr ic Compositions With Adjustable Temperature Coefficient", Materials Letters, 58, pp 3102-3106, 2004.

13. A. J. Moulson and J. M. Herbert, Electroceramics, Chapman \& Hall, p 234, 1990.

14. E. Yamashita, "Variational method for the anal ysis of microstrip-like transmission lines," IEEE Trans. Microwave Theory Tech, vol. 16, no. 8, pp. 529-535, Aug. 1968. 
15. R. Crampagne, M. Ahm adpanah, and J.-L. Gu iraud, "A simple method for deterring the green's function for a large class of MIC lin es having multilayered dielectric structures," IEEE Trans. Microwave Theory Tech, vol. 26, no. 2, pp. 82-87, Feb. 1978.

16. Y. Chang and I. C. Chang, "Sim ple method for the variational analysis of a generalized Ndielectric-layer transmission line," Electron. Lett., vol. 6, no. 3, pp. 49-50, Feb. 1970.

17. B. Bhat and S. K. Koul , "Stripline-like transmission lines for $\mathrm{m}$ icrowave integrated circuits", New Delhi: New Age International, p. 77. 2011.

18. A. Mohanram, G. L. M essing, and D. J. Gree n, "Densification and Sintering Viscosity of Low-Temperature Co-Fired Ceramics”, J. Am. Ceram. Soc., 88 [10], pp 2681-2689, 2005.

19. S. Dai, "Densification and crystallization in crystallizable low tem perature co-fired ceramics", Journal of materials Sciences. Published online Feb 18, 2012. Print version TBD. 


\section{DISTRIBUTION}

External distribution

1 Microelectronics Engineering National Nuclear Security Administration's Kansas City Plant Operated by Honeywell Federal Manufacturing \& Technologies, LLC

Attn: Dan Krueger

P.O. Box 419159

Kansas City, MO 64141-6159

Sandia distribution

$\begin{array}{llll}1 & \text { MS0959 } & \text { Adrian Casias } & 01832 \\ 1 & \text { MS0959 } & \text { Kenneth Peterson } & 01832 \\ 1 & \text { MS0348 } & \text { Christophe Rodenbeck } & 05352 \\ 1 & \text { MS0348 } & \text { Richard Knudson } & 05353 \\ & & & \\ 1 & \text { MS0899 } & \text { Technical Library } & 9536 \text { (electronic copy) } \\ 1 & \text { MS0359 } & \text { D. Chavez, LDRD Office } & 1911\end{array}$




\section{(1) Sandia National Laboratories}

